\title{
A hybrid approach combining interior-point and branch-and-bound methods applied to the problem of sugar cane waste
}

\section{Camila de Lima, Antonio Roberto Balbo, Thiago Pedro Donadon Homem \& Helenice de Oliveira Florentino Silva}

To cite this article: Camila de Lima, Antonio Roberto Balbo, Thiago Pedro Donadon Homem \& Helenice de Oliveira Florentino Silva (2017) A hybrid approach combining interior-point and branch-and-bound methods applied to the problem of sugar cane waste, Journal of the Operational Research Society, 68:2, 147-164, DOI: 10.1057/s41274-016-0027-0

To link to this article: https://doi.org/10.1057/s41274-016-0027-0

册 Published online: 21 Dec 2017.

Submit your article to this journal ๔

Џ Article views: 19

View Crossmark data ¿ 


\title{
A hybrid approach combining interior-point and branch- and-bound methods applied to the problem of sugar cane waste
}

\author{
Camila de Lima ${ }^{1 *}$, Antonio Roberto Balbo ${ }^{2}$, Thiago Pedro Donadon Homem ${ }^{3}$ \\ and Helenice de Oliveira Florentino Silva ${ }^{4}$ \\ ${ }^{1}$ Postgraduate Program in Computer Science and Computational Mathematics, ICMC, USP - University of São \\ Paulo, Av: Trabalhador São Carlense, 400, 13566-590 Centro, São Carlos, SP, Brazil; ${ }^{2}$ Department of \\ Mathematics, FC, UNESP - São Paulo State University, Av: Engenheiro Luiz Edmundo Carrijo Coube, 14-01, \\ 17033-360 Vargem Limpa, Bauru, SP, Brazil; ${ }^{3}$ IFSP - São Paulo Federal Institute of Education, Science and \\ Technology, Av: Zélia de Lima Rosa, 100, 18550-000 Portal dos Pássaros, Boituva, SP, Brazil; and ${ }^{4}$ Department \\ of Biostatistics, IBB, UNESP - São Paulo State University, Distrito de Rubião Junior S/N, 18618-970 Botucatu, \\ SP, Brazil
}

This paper proposes a hybrid approach for solving the multi-objective model related to the minimisation of sugar cane waste collection costs and/or the maximisation of produced energy by this waste, with the aid of strategies for solving multi-objective problems, which transform the problem into a set of single-objective problems. This approach combines the predictor-corrector primal-dual interior-point and branch-and-bound methods in order to solve these single-objective problems. The model consists in identifying the sugar cane varieties with the lowest waste collection costs, while simultaneously it aims to obtain the greatest amount of produced energy by this waste. The hybrid methods are implemented in $\mathrm{C}++$ programming language, and tests are performed to determine the efficient solutions in Pareto optimal sense of the multi-objective model and compare the performance of the hybrid method using the integrality test and without considering it. The mathematical results confirm that the proposed hybrid method for solving the aforementioned models presents good computational performance and reliable solutions.

Journal of the Operational Research Society (2017) 68(2), 147-164. doi:10.1057/s41274-016-0027-0; published online 21 September 2016

Keywords: integer programming; predictor-corrector primal-dual interior-point method; branch-and-bound method; sugarcane waste; multi-objective model

\section{Introduction}

Brazil is the world's largest sugar cane producer, according to CONAB (2015). In Brazil, it is estimated that the planted area of sugar cane in 2015/2016 harvest is about of 8,995.5 hectares and the latest forecast of sugar cane production in $2015 / 2016$ harvest is 658.7 million tonnes, an increase of $3.8 \%$ over the previous harvest.

During the mechanised harvesting, without burning sugar cane, large quantities of sugar cane waste are accumulate on the ground, such as tips, straw, leaves and culm fractions (Ripoli and Ripoli, 2004). It provides favourable conditions for the appearance of parasitic microorganisms and delays the emergence of new sugar cane sprouts, thereby compromises

*Correspondence: Camila de Lima, Postgraduate Program in Computer Science and Computational Mathematics, ICMC, USP - University of São Paulo, Av: Trabalhador São Carlense, 400, 13566-590 Centro, São Carlos, SP, Brazil.

E-mail: cadlima@yahoo.com.br the next crop. Thus, this biomass cannot be left in the soil and must be used.

A strategy that typically leads to good results consists in using the sugar cane waste through cogeneration. According to UNICA (2011), one tonne of bagasse can generate more than $300 \mathrm{kWh}$ to the power network and the same amount of straw can generate $500 \mathrm{kWh}$. Therefore, this remaining material should be collected and taken to the mills but, according to Ripoli (2002), this procedure is very expensive due to the amount of machinery involved.

In this paper, we present a multi-objective model based on Florentino and Pato (2014), which aims to minimise the cost of collecting and transporting the sugar cane waste to the processing centre and maximise the energy balance involved in this process, simultaneously. In order to investigate this multi-objective model, we use the weighted sum and the $\varepsilon$-constraint methods. These strategies redefine the problem as a set of single-objective problems, and then it is possible to determine the efficient solutions. Both strategies are described in Miettinen (1999) and Deb (2004). 
Therefore, a hybrid approach that combines the predictorcorrector primal-dual interior-point and branch-and-bound methods seeking to solve the single-objective problems is proposed. In this approach, the interior-point method, a variant method of those presented by Kojima et al (1989), Wu et al (1994) and Monteiro et al (1990), is used to get the real solutions and run until to achieve the stopping rules. Besides the primal and dual feasibility and complementary slackness, the integrality test proposed by Borchers and Mitchell (1992) is also used as criteria in this paper. After this, the branch-andbound method based on Borchers and Mitchell (1992) and Marcotte and Soland (1986) is employed to obtain the integer final solution of the problem. This proposed method is applied in an actual multi-objective model of sugar cane waste generated at a sugar mill located in São Paulo state, which cultivates 11 sugar cane varieties on 15 plots.

Section 2 of this paper presents the multi-objective mathematical models for minimising the sugar cane waste collection and transportation costs and maximising the energy balance, as well as the strategies to solve this multi-objective model. Section 2 describes the proposed hybrid method combining the predictor-corrector primal-dual interior-point and branch-and-bound methods, as well as an algorithm and a flowchart of the implementation method. Section 4 discusses the numerical results obtained using the strategies outlined in Section2, and the model data used for their application. Lastly, Section 5 offers our conclusions.

\subsection{Literature review}

The sugar cane industry is constantly expanding and, due to this fact, correlated problems increase and diversify. Thus, the investigation of techniques and resources to improve the planning and production process in general has been the subject of research. The literature review shows that works related to sugar cane have been widely studied in Brazil and in the world, in many different situations. As follows, some important works are highlighted.

A mathematical model representing the activities involved in the loading, transport and unloading of sugar cane was presented by Grisotto (1995). Higgins (1999) developed a large-scale integer programming model to optimise the decisions of harvest date, crop cycle length, and weather to fallow for all paddocks within Australian mill region. The logistical and economic complexity of the harvesting and transport system of an Australian sugar industry was studied by Higgins and Laredo (2006) through the development of a modelling framework. A mixed-integer linear programming model to solve the problem of cost minimisation of sugar cane removal and its transport systems of Cuba, including rail and road is presented by Milan et al (2006). Paiva and Morabito (2009) presented a mixedinteger linear programming model to optimise the selection process planning and lot sizing and the results were obtained by the generic mixed-integer programming solvers GAMS and
CPLEX. Rangel et al (2009) developed a simulation model to evaluate the influence of transactions on the mill and the impact on field operations. Jena and Poggi (2013) used preprocessing techniques and hot start associated with heuristic solutions to solve a mixed-integer programming model and investigate the sugar cane cultivation and harvesting planning. Lamsal et al (2013) presented a mixed-integer linear programming model of the sugar cane harvest logistic problems in Brazil. Silva et al (2013) proposed a multi-choice mixed-integer goal programming model for the aggregate production planning of a Brazilian sugar and ethanol milling company.

The following researchers are strictly related to this paper, since they consider sugar cane waste in the presented models. Ripoli (1991) presented a model to determine the straw efficiency from sugar cane, which is given by the relation between the amount of consumed energy in the fuel form by the machines and the amount of energy in the straw. Sartori et al (2001) presented mathematical optimisation models that minimise the amount of waste crop or maximise the energy contained in this waste determining the sugar cane varieties for planting. Lima (2009) proposed a multi-objective model that optimises the waste collection cost and/or energy balance generating a set of solutions that can be chosen according to the interests of the mill. The mathematical model presented by Florentino and Pato (2014) and Florentino et al (2011) aims to determine which sugar cane varieties should be planted to minimise sugar cane waste collection cost and maximise the energy balance of this waste, simultaneously. Florentino and Pato (2014) solved a problem which considers 10 varieties and 16 plots using genetic algorithms and Florentino et al (2011) used integer programming 0-1 method to solve an actual problem with 4 varieties and 16 plots.

The works cited here offer many contributions for researchers in this area, as well as reinforce the importance of sugar cane for generation of renewable energy. They show that optimisation models can greatly assist decision-making in mills. But few of these researchers deal with the selection of sugar cane varieties problem aiming to use the residual biomass from sugar cane, and furthermore present approximate solutions to the problem using heuristic methods. The residual biomass has become an important research topic because of the possibility of energy cogeneration and production of second-generation ethanol, from straw and bagasse of the sugar cane. Nowadays, the waste is an important source of energy, but it is necessary to obtain an economical and environmental way to collect and take advantage of this waste on field and transport to the processing centre. In this sense, this paper presents important contribution, since it offers an effective methodology for the determination of exact solutions to the problem. Other contributions are presented in the following Section 1.2.

\subsection{Contributions}

This paper contributes to the previous literature by proposing extensions on two levels: first, the multi-objective model to 
represent the problem and second, the resolution method used to solve it. The solved optimisation model in this paper is based on the multi-objective model presented by Florentino and Pato (2014), but in this case we use another constraint to delimit the plots number for each planted variety and a different instance with 15 varieties and 11 plots. These authors present a heuristic approach to solve the problem, determining approximate efficient solutions. However, we propose to determine the exact efficient solutions using a deterministic resolution method in this paper.

The idea of using the hybrid procedure between interiorpoint methods with integer programming methods was proposed and developed in Borchers and Mitchell (1992). According to the authors, the use of these methods associated with an integrality test proposed by them was efficient and, in the case of branching methods, it decreased the number of explored nodes necessary to solve the problem. Recently, Munari and Gondzio (2013) extended this method to the primal-dual interior-point and branch-and-cut-and-price methods to successfully solve NP-complete cutting and packing problems.

The main differences between our method and those proposed by the cited authors are in the search directions, which are determined, using a new and efficient predictorcorrector procedure variant from the one presented by Mehrotra (1992). A path following procedure that exploits the barrier parameter both in the predictor and corrector steps is considered, which prevents the interior points of being projected outside the feasible region, helps to perform the method with interior points far from the frontier problem, warranting their feasibility, and the possibility for the method to operate with long length steps, which improves its convergence. The proposed method also exploits the sparse structure of the search direction system in the predictor and corrector steps. Besides, it is considered the integrality test, proposed by Borchers and Mitchell (1992), in all steps of the predictor-corrector interior-point method. Therefore, it is a variant of the work presented by Homem et al (2011) with different orders of execution of the predictor and corrector steps, barrier parameter updating and the use of integrality test.

\section{Mathematical modelling}

There are many factors that determine the productivity of sugar cane. In order to have a good culture, a production planning should have done including analyses involving the climate, the physical, chemical and biological soil, varieties of sugar cane and its distribution, cultural practises, inputs, machinery and implements, factors of production, planting dates, among other services, aiming to get a high productivity minimising costs.

In Brazil, there are two different periods of the sugar cane planting in the South-Central region, which are named "sugar cane of one year"-which was planted from September to
October and it is harvested in about 12 months - and "sugar cane of one and a half year" - which was planted between January and March, and it is harvested around 18 months (Brandpo et al, 2009). This difference exists due to the sugar cane be a semipermanent culture that provides an average of four harvests or cuts. Among factors of production of sugar cane, the choice of variety is a major concern, since it is the only factor able to provide significant increases in productivity of the mill, without increasing the production costs (Andrade, 2001).

The choice of the sugar cane variety is very important because it is considered the basis of some decisions related to production and processing of raw materials, besides to be an option with the least cost to the producer. The varieties assume crucial role in crop yield and thus they enable to produce sugar cane quality and at lower cost. The varieties must have desirable characteristics such as high productivity, high sugar content, regrowth, no tipping and resistance to pests and diseases (Silveira et al, 2002). The choice of the variety is the key to the success of the crop. One variety per plot must be planted to decrease them to occur. The improved industrial varieties of sugar cane must be chosen and they must be adapted to local conditions of weather, such that these should be planted at no more than $30 \%$ of total acreage. Also the relief, soil fertility and the climate of the region must be considered (Silveira et al, 2002).

The sugar cane quality is measured mainly by the levels of sucrose and fibre. The sucrose (Pol \% of sugar cane) must be of $12.26 \%$. From a technological standpoint, the fibre comprises all insoluble substances contained in the raw material and its importance is related to the mechanised harvesting of sugar cane, with implications for the erect and smaller tipping of these, and for the industrialisation with impacts on grinding and thermal balance of the mill. The fibre levels in a standard sugar cane should range from 8 to $14 \%$ (Lavanholi, 2008).

The following presented model is based on the choice of varieties to be planted in the plots and this is based on the highlighted literature, which was detailed in the works of Ripoli (1991), Ripoli (2002) and Ripoli and Ripoli (2004). In this model, the maturation cycle is fixed in one year or one and a half year. The levels of fibre and sucrose (POL) are considered in this model, since the sugar cane quality is determined by such indicators and for the mill is more important the sucrose amount than sugar cane produced. Another constraint included in the model is that only one variety can be planted per plot to decrease the risk of loss through disease, as well as each one should not be planted at more than $30 \%$ of total acreage. The relief, soil fertility and climate of region features are also considered.

To produce energy from sugar cane waste, several steps are necessary: the straw in the fields is raked into piles and compressed by a baling machine. The bales are loaded into trucks and taken to a processing centre, where they are chopped and fed into a boiler to produce heat. The high cost of this procedure presents a problem for sugar mills. Hence, the way in which this waste is processed and used is an economic 
problem. Therefore, it is essential to analyse costs and energy balances when implementing a new operating system (Ripoli, 1991).

\subsection{Composition of the multi-objective function}

In this paper, we present a multi-objective model to determine which sugar cane varieties minimise sugar cane waste collection and transportation costs, while maximising the amount of energy produced by this waste.

Subsections 2.1.1 and 2.1.2 describe the calculations involved in formulating the multi-objective function, according to Ripoli (1991). To this end, we assume that sugar cane variety $i$, such that $i=1, \ldots, n$, was planted in plot $j$, with $j=1, \ldots, k$, each plot comprises $L_{j}$ hectares (ha) and it is located at a distance of $D_{j}$ kilometres $(\mathrm{Km})$ from the processing centre.

2.1.1. Sugarcane waste collection and transportation cost The collection and transportation cost, $C C_{i j}$, of sugar cane waste of the variety $i$ in plot $j$ is calculated by

$$
C C_{i j}=\left(C C L C_{i}+C T_{i j}\right) L_{j}
$$

where $C C L C_{i}$ is the cost, in $\mathrm{US} \$ \mathrm{ha}^{-1}$, of collecting, compacting and loading cane straw bales into the truck, calculated by (2.2), $C T_{i j}$ is the cost, in $\mathrm{US} \$ \mathrm{ha}^{-1}$, of transporting the waste from one hectare of sugar cane variety $i$ produced in plot $j$, in US\$ ha ${ }^{-1}$, calculated by (2.3) and $L_{j}$ is the area of plot $j$ (ha).

$$
\begin{gathered}
C C L C_{i}=\frac{Q_{i} C_{c c l}}{V_{i}} \\
C T_{i j}=\left(\frac{Q_{i}}{T_{C}}\right) D_{j} C_{f} P,
\end{gathered}
$$

where $Q_{i}$ is the estimated volume of waste produced by sugar cane variety $i$ per hectare, in $\mathrm{m}^{3} \mathrm{ha}^{-1} ; C_{c c l}$ is the cost to collect, compact and load the bales into the truck. in US\$ $\mathrm{t}^{-1}$; $V_{i}$ is the volume of one tonne ( $\mathrm{t}$ ) of compacted straw of sugar cane variety $i$, in $\mathrm{m}^{3} \mathrm{t}^{-1} ; T_{C}$ is the truck loading capacity $\left(\mathrm{m}^{3}\right)$; $D_{j}$ is the distance of the plot $j$ from the processing centre, in kilometres $(\mathrm{Km}) ; C_{f}$ is the fuel consumed by the truck in this distance $\left(\mathrm{L} \mathrm{km}^{-1}\right)$ and $P$ is the price of fuel, in US\$.L $\mathrm{L}^{-1}$.

2.1.2. Energy balance of sugarcane waste The energy balance of sugar cane waste related to the collection and transportation of variety $i$, planted in plot $j\left(E B_{i j}\right)$ is determined by

$$
E B_{i j}=E_{i j}-\left(E_{C C_{i j}}+E_{L_{i j}}+E_{T_{i j}}\right),
$$

where

$E_{i j}$ is the energy produced by cane waste of variety $i$ planted in plot $j$, in megajoule (MJ), calculated by (2.5); $E_{C C_{i j}}$ is the energy consumed to collect and compact the straw from sugar cane variety $i$ planted in plot $j$, calculated by (2.6); $E_{L_{i j}}$ is the energy consumed to load the waste from sugar cane variety $i$ planted in plot $j$, calculated by (2.7) and $E_{T_{i j}}$ is the energy consumed to transport the waste from sugar cane variety $i$ planted in plot $j$ to the processing centre, calculated by (2.8).

$$
\begin{gathered}
E_{i j}=E c_{i} M_{B_{i}} L_{j} \\
E_{C C_{i j}}=E c_{C C} L_{j} M_{B_{i}} \\
E_{L_{i j}}=E c_{L} L_{j} M_{B_{i}} \\
E_{T_{i j}}=E c_{T} D_{j} \frac{V_{i} L_{j}}{T_{C}}
\end{gathered}
$$

where $E c_{i}$ is the estimated calorific energy generated by one tonne of sugar cane waste resulting from harvesting variety $i$ $\left(\mathrm{MJ} \mathrm{t}^{-1}\right) ; M_{B_{i}}$ is the estimated mass of sugar cane waste generated per hectare of sugar cane variety $i$, in $\mathrm{t} \mathrm{ha}^{-1} ; E c_{C C}$ is the fuel energy consumption of the baling machine to collect and compact sugar cane waste, per unit mass (MJ tv); $E c_{L}$ is the energy consumed by the loader, per mass unit $\left(\mathrm{MJ} \mathrm{t}^{-1}\right)$ and $E c_{T}$ is the fuel energy consumption of the truck to transport the sugar cane waste $\left(\mathrm{MJ} \mathrm{km}^{-1}\right)$.

\subsection{Multi-objective model for minimising cost and maximising energy balance}

The problem consists in determining which of the varieties $i$, $(i=1,2, \ldots, n)$, must be planted in plots $j,(j=1,2, \ldots, k)$, that represent the lowest possible cost of sugar cane waste collection and transportation from the plot to the processing centre, while simultaneously providing the optimal energy balance.

In addition to these aims, it is necessary to satisfy the sugar cane sucrose and fibre constraints in order to meet the sugar mill's requirements of sugar cane quality and the demand for sugar and alcohol. Another important condition is to use the whole area for sugar cane cultivation, considering that only one type of variety can be planted per plot and each variety cannot be planted in more than $M$ plots.

The decision variables are $X_{i j}$, where $X_{i j}=1$ implies sugar cane variety $i$ should be planted in plot $j$; otherwise $X_{i j}=0$. The following multi-objective model (Florentino, 2006; Sartori et al, 2001) is presented for the sugar cane waste collection and transportation costs and energy balance:

$$
\text { Minimize: }\left\{\sum_{i=1}^{n} \sum_{j=1}^{k} C C_{i j} X_{i j},(-1) \sum_{i=1}^{n} \sum_{j=1}^{k} E B_{i j} X_{i j}\right\}
$$




$$
\begin{gathered}
\text { Subject to }: \sum_{i=1}^{n} \sum_{j=1}^{k} A_{i} L_{j} X_{i j} \geqslant T \bar{A} \\
T \bar{F}_{l} \leqslant \sum_{i=1}^{n} \sum_{j=1}^{k} F_{i} L_{j} X_{i j} \leqslant T \bar{F}_{u} \\
\sum_{i=1}^{n} X_{i j}=1, \quad \text { for all } j=1,2, \ldots, k \\
\sum_{j=1}^{k} X_{i j} \leqslant M \quad \text { for all } i=1,2, \ldots, n \\
X_{i j}=0 \text { or } 1, \quad i=1,2, \ldots, n \text { and } j=1,2, \ldots, k
\end{gathered}
$$

where $X_{i j}$ represents the decision variables to determine which sugar cane variety $i$ should be planted in plot $j ; C C_{i j}$ is the waste collection and transportation cost of sugar cane variety $i$, planted in plot $j$, expressed by (2.1) in Section 2.1.1; $E B_{i j}$ is the waste energy balance of sugar cane variety $i$, planted in plot $j$, calculated by $(2.4)$ in $2.1 .2 ; \bar{A}$ is the minimum quantity of fermentable sugar, i.e. sucrose content of the sugar cane variety; $A_{i}$ is the estimated sucrose production from variety $i(\mathrm{t} /$ ha) planted in area $L_{j} ; F_{i}$ is the estimated fibre content of variety $i ; \bar{F}_{l}$ represents the minimum quantity of sugar cane fibre; $\bar{F}_{u}$ represents the maximum quantity of sugar cane fibre; $T$ is the total area (ha) available for planting and $M$ is the maximum number of plots in which a variety $i$ can be planted.

The multi-objective function (2.9) minimises the collection and transportation cost and maximises the energy balance. Constraint (2.10) ensures the demand for fermentable sugar, constraint (2.11) ensures the demand for fibre, constraints (2.12) and (2.14) ensure that the entire area set aside for planting is cultivated and that only one sugar cane variety is planted per plot. Constraint (2.13) ensures that the same variety $i$ is not planted in more than $M$ plots.

\subsection{Strategies for solving the multi-objective model}

This paper presents two classical methods for solving multiobjective optimisation problems: the weighted sum method and the $\varepsilon$-constraint method. The use of these methods as a strategy to solve the problem (2.9)-(2.14) allows it to be redefined by means of simplified and single-objective problems, which will be presented in Sections 2.3.1 and 2.3.2.

It is important to note that both strategies can be performed without the other; however, determining the efficient solutions of multi-objective models is not so simple, and one strategy can help the other.

These single-objective problems allow the analysis of efficient solutions to the problem (2.9)-(2.14), using the Primal-Dual Interior-Point and Branch-and-Bound method described in Section 3 of this work. The applications of these problems and the results are discussed in Section 4.
2.3.1. Strategy 1: weighted sum method The weighted sum method, described by Deb (2004) and Miettinen (1999), consists of using a variable $\alpha$ that assumes values between 0 and 1, seeking the best values for balancing the multi-objective function. Hence, the multi-objective function is treated as a single-objective function and weighted in accordance with the $\alpha$ value. Equation (2.15) defines the new objective function, which is composed of sum of the collection cost and energy balance objective functions weighted by the $\alpha$ value as follows:

$$
\begin{aligned}
& \text { Minimize }:\left(\alpha \sum_{i=1}^{n} \sum_{j=1}^{k} C C_{i j} X_{i j}\right. \\
& \left.+(1-\alpha) \sum_{i=1}^{n} \sum_{j=1}^{k}\left(-E B_{i j}\right) X_{i j}\right) ; \alpha \in[0,1]
\end{aligned}
$$

$$
\text { Subject to : }(2.10)-(2.14)
$$

The optimal value of $C C_{i j}$ and $E B_{i j}$ is calculated for each $\alpha$ value. As the $\alpha$ changes over the interval [0,1], efficient solutions can be obtained and can draw a trade-off curve, also called a Pareto optimality curve, which correlates the values of $C C_{i j}$ and $E B_{i j}$. Efficient solutions are obtained as the result of the variation in the value of $\alpha$, among which the manager can choose the solution most suited to the company economic situation.

However, establishing an appropriate $\alpha$ weight parameter also depends on the scaling of each objective function coefficient, since the objective function coefficients of the collection and transportation costs and the energy balance have different orders of magnitude. To solve this problem, the objective coefficients must be normalised, because collection and transportation costs are in the order of $10^{3}$ (monetary values), and energy balance coefficients are in the order of $10^{6}$ (megajoule values). Thus, the objective function (2.15) is replaced by (2.16), in which the objective function coefficients are redefined by dividing the coefficients of cost and balance vectors by their respective infinity norm, according to

$$
\begin{aligned}
& \text { Minimize }:\left(\alpha \sum_{i=1}^{n} \sum_{j=1}^{k} \overline{C C}_{i j} X_{i j}\right. \\
& \left.+(1-\alpha) \sum_{i=1}^{n} \sum_{j=1}^{k}\left(-\overline{E B}_{i j}\right) X_{i j}\right) ; \alpha \in[0,1]
\end{aligned}
$$

where

$$
\begin{aligned}
\overline{C C}_{i j} & =\frac{C C_{i j}}{C C_{i j}^{\text {max }}} ; C C_{i j}^{\text {max }}=\max _{\substack{1 \leqslant i \leqslant n \\
1 \leqslant i \leqslant k}} C C_{i j} \text { and } \overline{E B}_{i j}=\frac{E B_{i j}}{E B_{i j}^{\text {max }}} ; E B_{i j}^{\text {max }} \\
& =\max _{\substack{1 \leqslant i \leqslant n \\
1 \leqslant i \leqslant k}} E B_{i j}
\end{aligned}
$$

with $i=1,2, \ldots, n$ and $j=1,2, \ldots, k$. 
2.3.2. Strategy 2: $\varepsilon$-Constraint method According to Deb (2004) and Miettinen (1999), the basic idea of the $\varepsilon$-constraint method is to keep one of the objectives as a function, and confine the rest of the objectives within user-specified values. Thus, the original problem is transformed into a set of singleobjective problem, which have a larger number of constraints.

In this paper, the collection and transportation cost is treated as an objective function, and the energy balance function becomes a constraint as follows:

$$
\text { Minimize : } \sum_{i=1}^{n} \sum_{j=1}^{k} C C_{i j} X_{i j}
$$

Subject to : (2.10)-(2.14) and

$$
\sum_{i=1}^{n} \sum_{j=1}^{k} E B_{i j} X_{i j} \geqslant \varepsilon
$$

According to this strategy, in (2.18), $\varepsilon$ represents the minimum energy balance that the manager wishes to maintain. Thus, the problem (2.17) consists in determining which sugar cane varieties should be planted to achieve the minimum cost, respecting the same previous constraints in (2.10)-(2.14), coupled with the constraint in (2.18).

\section{Hybrid procedures for the predictor-corrector primal-dual interior-point and branch-and- bound methods}

Seeking to solve the multi-objective model (2.9)-(2.14) described in Section 2.2" section using the strategies presented in 2.3.1 and 2.3.2, a hybrid PDIPBB procedure is proposed combining the predictor-corrector primal-dual interior-point (PDIP) and branch-and-bound (BB) methods.

The interior-point method presented was initially proposed by Karmarkar (1984), and it is inserted into the primal-dual method developed by Kojima et al (1989) and Monteiro et al (1990) and then exploited in Fang and Puthenpura (1993). It is also defined as a variant of the predictor-corrector procedure presented by Mehrotra and Sun (1990) and implemented by Lustig et al (1992), with improvements proposed by Wu et al (1994). Moreover, it differs from Mehrotra (1992) by using the barrier parameter information in the predictor step. The branch-and-bound method presented is based on Land and Doig (1960), Marcotte and Soland (1986) and Borchers and Mitchell (1992), considering the integrality test proposed by the last one.

We propose some differences in the interior-point method in this paper. The predictor-corrector procedure is a variant of the one presented by Mehrotra (1992) and considers a path following procedure that exploits the barrier parameter to calculate the search directions, both in the predictor and corrector steps. It warranties the feasibility because the method is performed with interior points far away of the problem frontier, besides improving convergence to the global minimum since the possibility to operate with long length steps. The proposed method also exploits the sparse structure of the search direction system in the predictor and corrector steps.

The idea of using interior-point methods with integer programming methods was proposed and developed in Borchers and Mitchell (1992). The authors also proposed an integrality test to be used in combination with the procedure, in order to obtain faster and more efficient solutions. In the case of branching methods, this test decreases the branching number to solve the problem. In this way, we propose the hybrid PDIPBB approach combining interior-point and integer methods in this paper, where the PDIP method is used to obtain the optimal real solution, satisfying the classic stopping rules and the integrality test proposed by Borchers and Mitchell (1992), which is considered in all steps of the method. Using this solution, the BB method determines the optimal integer solution, respecting the constraints of the problem.

The developed method is also a variant that was presented in Homem et al (2011) including some modifications that enabled improvements in the computational performance and results. In Homem et al (2011), the predictor step is performed in pair iterations, and the corrector step in odd iterations, while in this work the predictor and corrector procedures are performed in the same iteration. Homem et al (2011) used the integrality test proposed by Borchers and Mitchell (1992) together with the duality gap, as proposed by cited authors. In this work, the integrality test is used together with the optimality criteria of the predictor-corrector primal-dual interior-point method, where verifies the primal feasibility, the dual feasibility and the complementarity relation. The test was performed in this way to avoid that the PCPDIP method was interrupted in advance and more branches than necessary were generated. In both studies, the barrier parameter is updated as it is proposed in Wright (1997), but in this work we used a convergence accelerator, which is based on the same author and decreases the iterations number of PCPDIP method. Thus, the method is defined as follows:

Consider a linear programming problem (LPP) of minimising linear functions, with equality constraints and bounded variables, expressed as follows:

$$
\begin{array}{r}
\text { Minimize } c^{\mathrm{T}} x \\
\text { Subjectto : }\left\{\begin{array}{c}
A x=b \\
l \leqslant x \leqslant u
\end{array}\right.
\end{array}
$$

where $A \in \mathfrak{R}^{\mathfrak{m} * \mathfrak{n}}$, such that $A$ has rank $m, b \in \mathfrak{R}^{\mathfrak{m}}, x, c, u \in \mathfrak{R}^{\mathfrak{n}}$. It follows that the LPP problem (3.1) is equivalent to 


$$
\begin{array}{r}
\text { Minimize } c^{\mathrm{T} x} \\
\text { Subject to : }\left\{\begin{array} { c } 
{ \text { Minimize } c ^ { \mathrm { T } } x } \\
{ x \geqslant l } \\
{ x \leqslant u }
\end{array} \Leftrightarrow \text { Subjectto : } \left\{\begin{array}{c}
A x=b \\
x-r=l \\
x+z=u \\
r \geqslant 0, z \geqslant 0
\end{array}\right.\right.
\end{array}
$$

where $z, r \in \mathfrak{R}^{\mathfrak{n}}$ are slack and surplus variables, respectively.

Then, the LPP (3.2) is redefined through an unconstrained NLPP, which is defined from a Logarithmic Barrier Lagrangian function $L(x, w, z, r, y, s)$ :

$$
\begin{gathered}
L(x, w, z, r, y, s)=c^{T} x+w^{T}(b-A x)+y^{T}(x+z-u) \\
+s^{T}(-x+r+l)-\mu \sum_{i=1}^{n} \ln \left(z_{i}\right)-\mu \sum_{i=1}^{n} \ln \left(r_{i}\right)
\end{gathered}
$$

where $z>0$ and $r>0$ are the primal variables, and $w \in \mathfrak{R}^{\mathfrak{m}}$ and $y, s \in \mathfrak{R}^{\mathfrak{n}}$ are the dual variables of the problem associated with the three equality constraints in (3.2), such that $y \geqslant 0$ and $s \geqslant 0$, and $\mu>0$ is the barrier parameter.

From $L_{(x, w, z, r, y, s)}$ expressed in (3.3), we have the following Karush-Kuhn-Tucker (KKT) optimality conditions for this problem, which are used to develop the primal-dual interiorpoint method:

$$
\begin{gathered}
\frac{\partial L}{\partial x}=0 \Leftrightarrow c-A^{T} w+y-s=0 \\
\frac{\partial L}{\partial w}=0 \Leftrightarrow b-A x=0 \\
\frac{\partial L}{\partial y}=0 \Leftrightarrow x+z-u=0 \\
\frac{\partial L}{\partial s}=0 \Leftrightarrow-x+r-l=0 \\
\frac{\partial L}{\partial z}=0 \Leftrightarrow y-\mu Z^{-1} e=0 \\
\frac{\partial L}{\partial r}=0 \Leftrightarrow s-\mu R^{-1} e=0
\end{gathered}
$$

where $Z, Y, R$ and $S$ are the diagonal matrices whose diagonal elements are $z_{i}, y_{i}, r_{i}$ and $s_{i}, i=1, \ldots, n$ respectively, and $e=(1, \ldots, 1)^{T}$.

Considering a problem with lower variables bounded in zero, in other words $l=0$, the constraint $x-r=l$ seen in (3.2) becomes $x=r$, so the condition in (3.7) is not considered and the condition in (3.9) is replaced by

$$
s-\mu X^{-1} e=0 \quad \Leftrightarrow \quad X S e-\mu e=0,
$$

where $X$ is the diagonal matrix, whose diagonal elements are $x_{i}$.
The KKT conditions presented in (3.4)-(3.6), (3.8) and (3.10), rewritten and represented by the equivalent system (3.11), are considered in the following sections to define important issues concerning about the proposed hybrid method, such as search directions, step sizes, stopping criteria and updating the barrier parameter.

$$
F(x, w, z, y, s)=\left(\begin{array}{c}
A^{T} w-y+s-c \\
A x-b \\
x+z-u \\
Z Y e-\mu e \\
X S e-\mu e
\end{array}\right)=0
$$

In order to simplify the notations, we denote the solution set $\Omega^{0}$, which describes the interior points for problem (3.2) as follows:

$$
\begin{aligned}
& \Omega^{0}=\left\{(x, w, z, y, s) \mid A^{T} w+s-y=c, A x=b,\right. \\
& x+z=u,(x, z, y, s)>0\}
\end{aligned}
$$

The predictor-corrector method proposed here is a variant of the one put forward by Mehrotra (1992), but differs from the latter which uses the barrier parameter information in the predictor step, thus improving the method's efficiency by preventing the defined points of moving closer to the boundary of the problem. In the corrector step, this resets the directions using information of second-order approximants of the conditions of complementarity, improving the convergence of the method. Moreover, the predictor and corrector procedures are performed in same step.

\subsection{Search directions}

The search directions used in the proposed hybrid method are determined in this section. Initially, the search directions for the predictor procedure are calculated in Section 3.1.1, while the search directions for the corrector procedure are updated in Section 3.1.2.

3.1.1. Predictor step search directions Supposing that, in an iteration $\mathrm{k}$, a point $h^{k}$ satisfies the KKT conditions expressed by (3.4)-(3.6), (3.8) and (3.10). The definition of the new point $h^{k+1}$ depends on the calculation of a search direction and in a step size in this direction. Without considering the step size in an initial analysis, the new point $h^{k+1}$ in iteration $k+1$ is defined by

$$
\left(\begin{array}{c}
x^{k+1} \\
w^{k+1} \\
z^{k+1} \\
y^{k+1} \\
s^{k+1}
\end{array}\right)=\left(\begin{array}{c}
x^{k}+d_{x}^{k} \\
w^{k}+d_{w}^{k} \\
z^{k}+d_{z}^{k} \\
y^{k}+d_{y}^{k} \\
s^{k}+d_{s}^{k}
\end{array}\right)
$$


After this, to obtain the new point $h^{k+1}$ requires determining the direction $d^{(k)}=\left(d_{x}^{k}, d_{w}^{k}, d_{z}^{k}, d_{y}^{k}, d_{s}^{k}\right)^{T}$. Following the steps of Newton's method, $d^{(k)}$ can be obtained by solving the following system (3.14):

$$
J\left(h^{(k)}\right) d^{(k)}=-F\left(h^{(k)}\right)
$$

which is equivalent to (3.15) as follows:

$$
\left(\begin{array}{ccccc}
0 & A^{T} & 0 & -I & I \\
A & 0 & 0 & 0 & 0 \\
I & 0 & I & 0 & 0 \\
0 & 0 & Y & Z & 0 \\
S & 0 & 0 & 0 & X
\end{array}\right)\left(\begin{array}{c}
d_{x}^{k} \\
d_{w}^{k} \\
d_{z}^{k} \\
d_{y}^{k} \\
d_{s}^{k}
\end{array}\right)=\left(\begin{array}{c}
g^{k} \\
t_{1}^{k} \\
t_{2}^{k} \\
q_{1}^{k} \\
q_{2}^{k}
\end{array}\right)
$$

where

$$
\begin{gathered}
g^{k}=c-A^{T} w^{k}-s^{k}+y^{k} \\
t_{1}^{k}=b-A x^{k} \\
t_{2}^{k}=u-x^{k}-z^{k} \\
q_{1}^{k}=\mu_{k} e-Z_{k} Y_{k} e \\
q_{2}^{k}=\mu_{k} e-X_{k} S_{k} e
\end{gathered}
$$

and $g^{k}$ is the dual residual, $t_{1}^{k}$ and $t_{2}^{k}$ are the primal residuals and, $q_{1}^{k}$ and $q_{2}^{k}$ are the complementary slackness in the predictor step.

The operations in (3.15) result in equations (3.21)-(3.25) as follows:

$$
\begin{gathered}
A^{T} d_{w}^{k}+d_{s}^{k}-d_{y}^{k}=g^{k} \\
A d_{x}^{k}=t_{1}^{k} \\
d_{x}^{k}+d_{z}^{k}=t_{2}^{k} \\
Y_{k} d_{z}^{k}+Z_{k} d_{y}^{k}=q_{1}^{k} \\
S_{k} d_{x}^{k}+X_{k} d_{s}^{k}=q_{2}^{k}
\end{gathered}
$$

The directions below (3.26), (3.27) and (3.28) were obtained directly from (3.23), (3.24) and (3.25), respectively.

$$
\begin{gathered}
d_{z}^{k}=-d_{x}^{k}+t_{2}^{k} \\
d_{y}^{k}=Z_{k}^{-1}\left(q_{1}^{k}-Y_{k} d_{z}^{k}\right) \\
d_{s}^{k}=X_{k}^{-1}\left(q_{2}^{k}-S_{k} d_{x}^{k}\right)
\end{gathered}
$$

Combining equations (3.21) and (3.22) with the results found in (3.26)-(3.28), the directions are obtained as follows:

$$
\begin{gathered}
d_{w}^{k}=\left(A \theta_{k} A^{T}\right)^{-1}\left[A \theta_{k}\left(g^{k}+\pi^{k}\right)+t_{1}^{k}\right] \\
d_{x}^{k}=\theta_{k}\left(A^{T} d_{w}^{k}-g^{k}-\pi^{k}\right)
\end{gathered}
$$

where

$$
\theta_{k}^{-1}=\left(X_{k}^{-1} S_{k}+Z_{k}^{-1} Y_{k}\right)
$$

is a dual normal matrix and

$$
\pi^{k}=Z_{k}^{-1}\left(q_{1}^{k}-Y_{k} t_{2}^{k}\right)+X_{k}^{-1} q_{2}^{k}
$$

is a residual vector, both dependent on the primal, dual and complementarity equations.

Since matrix $A \theta A^{T}$ is symmetric positive defined in (3.29), direction $d_{w}^{k}$ can be determined by using the Cholesky decomposition. It is then possible to obtain direction $d_{x}^{k}$ using (3.30). The remaining components of the direction vectors $d_{z}^{k}$, $d_{y}^{k}$ and $d_{s}^{k}$ in (3.26), (3.27) and (3.28), respectively, are calculated easily.

3.1.2. Corrector step search directions Analogously to Section 3.1.1, section, the search direction $\tilde{d}^{(k)}$ for the corrector procedure is determined by solving the following linear system:

$$
J\left(h^{(k)}\right) \tilde{d}^{(k)}=-\tilde{F}\left(h^{(k)}\right)
$$

where $\tilde{F}\left(h^{(k)}\right)$ is obtained by considering second-order approximations in the residuals of the complementarity conditions, $q_{1}^{k}$ and $q_{2}^{k}$, calculated in the predictor step in (3.19) and (3.20).

$$
\left(\begin{array}{ccccc}
0 & A^{T} & 0 & -I & I \\
A & 0 & 0 & 0 & 0 \\
I & 0 & I & 0 & 0 \\
0 & 0 & Y & Z & 0 \\
S & 0 & 0 & 0 & X
\end{array}\right)\left(\begin{array}{c}
\tilde{d}_{x}^{k} \\
\tilde{d}_{w}^{k} \\
\tilde{d}_{z}^{k} \\
\tilde{d}_{y}^{k} \\
\tilde{d}_{s}^{k}
\end{array}\right)=\left(\begin{array}{c}
g^{k} \\
t_{1}^{k} \\
t_{2}^{k} \\
\tilde{q}_{1}^{k} \\
\tilde{q}_{2}^{k}
\end{array}\right)
$$

where $g^{k}, t_{1}^{k}$ and $t_{2}^{k}$ were defined in (3.16), (3.17) and (3.18) in Section 3.1.1,

$$
\begin{aligned}
& \tilde{q}_{1}^{k}=\mu_{k} e-Z_{k} Y_{k} e-D_{z}^{k} D_{y}^{k} e \\
& \tilde{q}_{2}^{k}=\mu_{k} e-X_{k} S_{k} e-D_{x}^{k} D_{s}^{k} e
\end{aligned}
$$

are residuals generated by second-order Taylor approximation, and $D_{x}^{k}, D_{z}^{k}, D_{y}^{k}$ and $D_{s}^{k}$ are the diagonal matrices whose 
diagonal components are $\left(d_{x}^{k}\right)_{i},\left(d_{z}^{k}\right)_{i}, \quad\left(d_{y}^{k}\right)_{i}$ and $\left(d_{s}^{k}\right)_{i}$, $i=1, \ldots, n$, respectively.

In the procedure of the corrector step, the direction values $d_{x}^{k}, d_{z}^{k}, d_{y}^{k}$ and $d_{s}^{k}$, calculated in the predictor step, are used to redefine residuals $\tilde{q}_{1}^{k}$ and $\tilde{q}_{2}^{k}$ in (3.35) and (3.36), respectively. Thus, the new directions $\left(\tilde{d}_{x}^{k}, \tilde{d}_{z}^{k}, \tilde{d}_{w}^{k}, \tilde{d}_{s}^{k}, \tilde{d}_{y}^{k}\right)$ can be calculated using the same steps taken to determine the directions of the predictor step, in Section 3.1.1, obtaining the following equations:

$$
\begin{gathered}
\tilde{d}_{w}^{k}=\left(A \theta_{k} A^{T}\right)^{-1}\left[A \theta_{k}\left(g^{k}+\tilde{\pi}^{k}\right)+t_{1}^{k}\right] \\
\tilde{d}_{x}^{k}=\theta_{k}\left(A^{T} \tilde{d}_{w}^{k}-g^{k}-\tilde{\pi}^{k}\right) \\
\tilde{d}_{z}^{k}=-\tilde{d}_{x}^{k}+t_{2}^{k} \\
\tilde{d}_{y}^{k}=Z_{k}^{-1}\left(\tilde{q}_{1}^{k}-Y_{k} \tilde{d}_{z}^{k}\right) \\
\tilde{d}_{s}^{k}=X_{k}^{-1}\left(\tilde{q}_{2}^{k}-S_{k} \tilde{d}_{x}^{k}\right)
\end{gathered}
$$

where $\theta_{k}$ is defined in (3.31) and

$$
\tilde{\pi}^{k}=Z_{k}^{-1}\left(\tilde{q}_{1}^{k}-Y_{k} f^{k}\right)+X_{k}^{-1} \tilde{q}_{2}^{k}
$$

\subsection{Step size}

According to Bazaraa et al (1993), after determining the directions, the step size in this direction, in search of a new point $\left(x^{k+1}, w^{k+1}, z^{k+1}, y^{k+1}, s^{k+1}\right)$, is calculated as described below:

$$
\begin{array}{r}
x^{k+1}=x^{k}+\alpha_{k}^{P} \tilde{d}_{x}^{k} \\
z^{k+1}=z^{k}+\alpha_{k}^{P} \tilde{d}_{z}^{k} \\
w^{k+1}=w^{k}+\alpha_{k}^{D} \tilde{d}_{w}^{k} \\
y^{k+1}=y^{k}+\alpha_{k}^{D} \tilde{d}_{y}^{k} \\
s^{k+1}=s^{k}+\alpha_{k}^{D} \tilde{d}_{s}^{k}
\end{array}
$$

where $\alpha_{k}^{P}$ is the primal step size and $\alpha_{k}^{D}$ is the dual step size, as specified below:

- The step size for primal variables $\alpha_{k}^{P}$ is obtained through (3.44), without violating the nonnegativity requirements of the primal variables

$$
\alpha_{k}^{P}=\min \left\{1,-\frac{\beta x_{i}^{k}}{\tilde{d} x_{i}^{k}},-\frac{\beta z_{i}^{k}}{\tilde{d} z_{i}^{k}} \mid \tilde{d} x_{i}^{k}, \tilde{d} z_{i}^{k}<0\right\}
$$

- The step size for dual variables $\alpha_{k}^{D}$ is calculated by (3.45), without violating the nonnegativity requirements of the dual variables

$$
\alpha_{k}^{D}=\min \left\{1,-\frac{\beta y_{i}^{k}}{\tilde{d} y_{i}^{k}},-\frac{\beta s_{i}^{k}}{\tilde{d} s_{i}^{k}} \mid \tilde{d} y_{i}^{k}, \tilde{d} s_{i}^{k}<0\right\}
$$

where $0<\beta<1$.

\subsection{Stopping rules}

The stopping rules proposed here are based on Wright (1997). The following tests (3.46)-(3.48) are presented to ensure which is the optimal solution of the problem, deciding when the solution obtained in a current iteration is sufficiently close to the optimal solution, since interior-point algorithms do not find exact solutions.

- Primal feasibility:

$$
\frac{\left\|t_{1}^{k}\right\|}{\|b\|+1}=\frac{\left\|b-A x^{k}\right\|}{\|b\|+1} \leqslant \varepsilon_{1}
$$

- Dual feasibility:

$$
\frac{\left\|g^{k}\right\|}{\|c\|+1}=\frac{\left\|c-A^{T} w^{k}-s^{k}+y^{k}\right\|}{\|c\|+1} \leqslant \varepsilon_{2} ;
$$

- Complementary slackness:

$$
\left\|\tilde{q}_{1}^{k}\right\|<\varepsilon_{3} \text { and }\left\|\tilde{q}_{2}^{k}\right\|<\varepsilon_{4},
$$

where $\varepsilon_{1}, \varepsilon_{2}, \varepsilon_{3}, \varepsilon_{4}>0$ are small positive tolerances.

- Integrality test : In addition to the criteria presented here, we add the following integrality test according to Borchers and Mitchell (1992), where a heuristic is used to determine if any zero-one variables are converging to fractional variables. If this occurs, the algorithm branches on the current subproblem to create two new subproblems. This criterion helps to evaluate solution integrality based on the fact that for a fractional variable, the ratios $\frac{x_{i}^{k+1}}{x_{i}^{k}}$ and $\frac{z_{i}^{k+1}}{z_{i}^{k}}$ go to one, and $\frac{y_{i}^{k+1}}{y_{i}^{k}}$ and $\frac{s_{i}^{k+1}}{s_{i}^{k}}$ go to zero, as the solution approaches optimality. Moreover, this prevents the algorithm from branching as early as possible, providing a safeguard to reduce the total number of subproblems solved. Thus, a zero-one variable is fractional when it satisfies:

$$
\begin{aligned}
\left|\frac{x_{i}^{k+1}}{x_{i}^{k}}-1\right| & <0.1 \\
\left|\frac{z_{i}^{k+1}}{z_{i}^{k}}-1\right| & <0.1 \\
\frac{y_{i}^{k+1}}{y_{i}^{k}} & <0.6 \\
\frac{s_{i}^{k+1}}{s_{i}^{k}} & <0.6
\end{aligned}
$$


The inequality values were adopted because, according to the aforecited authors, the ratios of the $y$ and $s$ variables do not reach zero as rapidly as the ratios of the $x$ and $z$ variables reach one.

Based on the implementation of the algorithm presented in Section 3.5, several computational tests were performed to solve the multi-objective model described in Section 2.2, related to strategies 1 and 2 presented in Sections 2.3.1 and 2.3.2. It was found that the integrality test proposed by Borchers and Mitchell (1992) actually decreases the number of branches of the branch-and-bound method, reducing the computational time required to perform the procedure.

\subsection{Barrier parameter}

The barrier parameter $\mu_{k}$ is updated using (3.50), based on Wright (1997):

$$
\mu_{k}=\min \left\{\sigma \mu_{k}^{1}, \sigma \mu_{k}^{2}\right\} \text { for a constant } 0<\sigma<1,
$$

where parameter $\sigma$ is used to accelerate the convergence of the iterative process and parameters $\mu_{k}^{1}$ and $\mu_{k}^{2}$ are a dot-product (inner product) that involves the primal variables $x^{k}$ and $z^{k}$, and the dual variables $s^{k}$ and $y^{k}$, respectively, are calculated by

$$
\mu_{k}^{1}=\frac{\left(x^{k}\right)^{T} s^{k}}{n} ; \quad \mu_{k}^{2}=\frac{\left(z^{k}\right)^{T} y^{k}}{n} .
$$

\subsection{Predictor-corrector primal-dual interior-point and branch-and-bound algorithm (PDIPBB)}

Steps 1 to 8 of the PDIPBB algorithm are based on Wu et al (1994) and Kojima et al (1989). This algorithm is completed in steps 9 to 15 by the branch-and-bound method which is used to obtain the optimal integer solution of the problem, based on Borchers and Mitchell (1992) and Marcotte and Soland (1986).

\section{Step 1: Initialization}

Adjust $k=0$. Choose an arbitrary point: $\left(x^{0}, w^{0}, z^{0}, y^{0}, s^{0}\right) \in$ $\Omega^{0}$ and choose $\varepsilon_{1}, \varepsilon_{2}, \varepsilon_{3}$ and $\varepsilon_{4}$ as sufficiently small positive numbers.

Step 2: Checking optimality

If the criteria defined in (3.46), (3.47), (3.48) and (3.49) are satisfied, STOP the predictor-corrector primal-dual method, because the unbounded solution is optimal, and go to branchand-bound, in step 9. Otherwise, go on to the next step.

Step 3: Intermediate calculations-predictor

Calculate $g^{k}, t_{1}^{k}, t_{2}^{k}, q_{1}^{k}$ and $q_{2}^{k}$ using (3.16)-(3.20), $\mu_{k}$ using (3.50), matrix $\theta$ using (3.31) and the vector $\pi^{k}$ using (3.32).

Step 4: Finding search directions-predictor

Calculate search directions $d_{x}^{k}, d_{w}^{k}, d_{z}^{k}, d_{r}^{k}, d_{y}^{k}$ and $d_{s}^{k}$ for the predictor procedure, using (3.30)-(3.28).
Step 5: Intermediate calculations-corrector

Update the residuals $\tilde{q}_{1}^{k}$ and $\tilde{q}_{2}^{k}$ using (3.35) and (3.36), and $\tilde{\pi}^{k}$ using (3.42).

Step 6: Finding search directions-corrector

Calculate $\tilde{d}_{x}^{k}, \tilde{d}_{w}^{k}, \tilde{d}_{z}^{k}, \tilde{d}_{r}^{k}, \tilde{d}_{y}^{k}$ and $\tilde{d}_{s}^{k}$ for the corrector step using (3.38)-(3.41).

Step 7: Computing step size

Calculate step sizes $\alpha_{k}^{P}$ and $\alpha_{k}^{D}$ using (3.44) and (3.45).

Step 8: Moving to a new solution

Update $x^{k+1}, w^{k+1}, z^{k+1}, y^{k+1}$ and $s^{k+1}$ using (3.43). Adjust $k=k+1$ and return to step 2 .

Step 9: Starting the Branch-and-Bound method

For each $x_{i}$, if $x_{i} \geqslant 0.99$, assume $x_{i}=1$ and use $x_{h}=0$ for all the remaining $h(h=1, \ldots, n$ and $h \neq i)$. Otherwise, if $x_{i}$ is a fractional variable and satisfied the integrality test (3.49), proceed to step 10.

Step 10: Starting the list of subproblems to be evaluated:

When solving the relaxed problem (Pr), if $x^{*} \in \mathfrak{R}^{\mathfrak{n}}$ is not feasible for the problem with whole variables (Pi), take an index $j \in I, I=1,2, \ldots, n$, whose variable $x_{j}^{*}$ has a fractional value, and create the subproblems $\left(\operatorname{Pr}_{1}\right)$ and $\left(\operatorname{Pr}_{2}\right)$, adding the constraints $\left(x_{j} \leqslant \operatorname{int}\left(x_{j}^{*}\right)\right)$ and $\left(x_{j} \geqslant \operatorname{int}\left(x_{j}^{*}\right)+1\right)$ to the problems (Pr), respectively, where $\operatorname{int}\left(x_{j}^{*}\right)$ is the integer part of $x_{j}^{*}$. Now, there are two problems to be evaluated (branched): $\left(\operatorname{Pr}_{1}\right)$ and $\left(\operatorname{Pr}_{2}\right)$. Proceed to step 11 .

Step 11: Choosing one of the subproblems to evaluate:

If there is a subproblem in the subproblems list to be evaluated using the PDIP, choose one and go to step 12 . Otherwise, go to the end (Figure 1).

Step 12: Evaluating the chosen subproblem:

Supposing $\left(\operatorname{Pr}_{1}\right)$ was chosen, it is evaluated by: Solve the continuous problem $\left(\operatorname{Pr}_{1}\right)$ through the steps 1-8; If the solution $\left(x_{1}^{*}\right)$ is feasible for $(\mathrm{Pr})$ and unfeasible for $(\mathrm{Pi})$ and the $Z \mathrm{Pr}_{1}$ value is less than $Z^{*}$, go to step 14. Otherwise, go to step 13 .

Step 13: Performing the probe:

A subproblem is probed if one of the following cases occurs:

- The solution to the problem under evaluation is unfeasible for (Pr).

- The solution to the problem under evaluation is feasible for (Pr) and unfeasible for (Pi) and the objective function of the subproblem is equal to or greater than $Z^{*}$. Go to step 11 .

Step 14: Dividing the subproblem into two and putting them in the subproblems list to be evaluated:

Divide the subproblem $\left(\operatorname{Pr}_{1}\right)$ into two new ones $\left(\operatorname{Pr}_{11}\right)$ and $\left(\operatorname{Pr}_{12}\right)$, adding the constraints $\left(x_{j} \leqslant \operatorname{int}\left(x_{j}^{*}\right)\right)$ and $\left(x_{j} \geqslant \operatorname{int}\left(x_{j}^{*}\right)+1\right)$ to the subproblem $\left(\operatorname{Pc}_{1}\right)$, where $x_{j}^{* 1}$ is a fractional value. Now, one has subproblems $\left(\mathrm{Pc}_{2}\right),\left(\mathrm{Pc}_{11}\right)$ and $\left(\mathrm{Pc}_{12}\right)$ to be evaluated by the PDIP method through the 


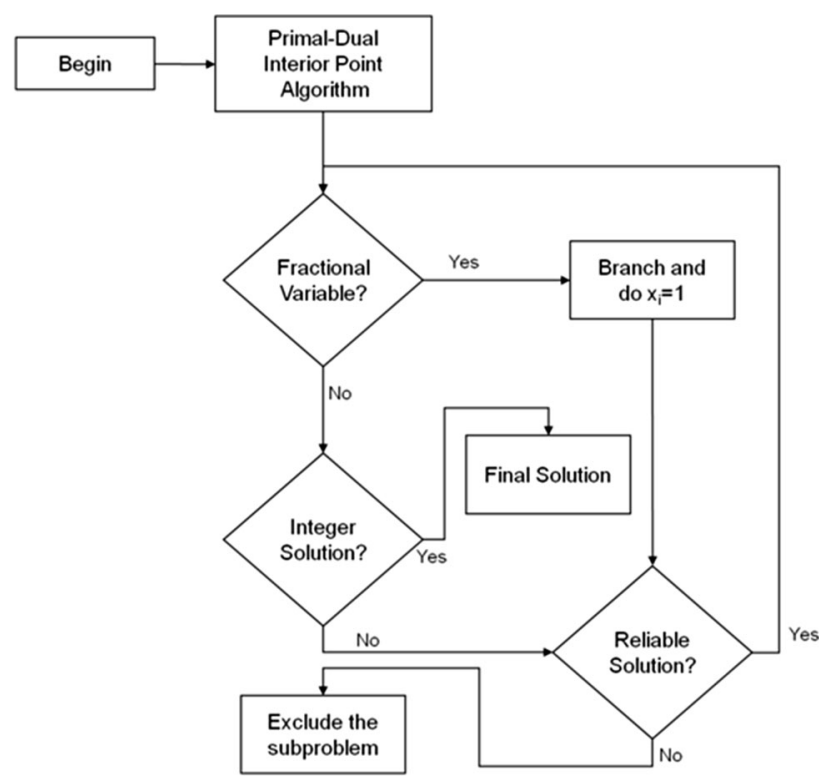

Figure 1 Flowchart of the implemented method.

steps 1-8.

Go to step 10.

Step 15: End

The optimal value for $Z \mathrm{Pi}$ is given by the best feasible value $Z^{*}$ found.

\section{Results}

The hybrid algorithm PDIPBB was implemented in C++ language using the Borland $\mathrm{C}++$ Builder 6 compiler, and it was run on an IBM/PC computer equipped with an Intel Core2 Duo $2.0 \mathrm{GHz}$ processor, $4 \mathrm{MB}$ of memory and Windows 7 Home Premium operating system with Service Pack 1.

The results obtained were applied to an actual model of sugar cane waste from a sugar mill located in São Paulo state, Brazil, which cultivates 11 sugar cane varieties in 15 plots. The data relating to this model are presented in Section 4.1.

Using the data presented in Section 4.1, we applied the proposed hybrid PDIPBB method described in Section 3 to the single-objective models relative to strategies 1 and 2 , described in Sections 2.3.1 and 2.3.2. The results of this application are discussed in Section 4.2.

\subsection{Data applied to the mathematical models}

The agronomic data relating to the collection and transportation cost and energy balance of the sugar cane waste that were used to implement the model were taken from Florentino (2006), Tolentino (2007), Lima (2009) and Sartori et al (2001). These data are presented in Tables 1, 2 and 3.

Table 1 lists data on 11 varieties (SP701284, SP706163, SP701143，SP71-3146, NA56-79, RB72454, RB855536,
SP791011, RB855113, RB 806043 and RB835486). Table 2 lists the costs, energy consumption and recommendations for the sugar cane varieties. Table 3 presents the data of the 15 aforementioned plots. The data presented in these tables were used in the composition of equations and constraints of the model in order to apply the hybrid method described in Section 3 to obtain the results.

It may not be advantageous for the sugar mill to plant only one sugar cane variety in all or most of the plots. To avoid this problem, we inserted the constraint (2.13) to limit the number of plots in which the same variety is planted. Therefore, to meet the sugar mill requirements, we considered that only 4 plots $(M=4)$ should be cultivated with the same sugar cane variety.

\subsection{Results obtained by applying the hybrid method}

The multi-objective model (2.9)-(2.14) is solved by means of strategies 1 and 2 described in Section 2.3, applying the proposed hybrid PDIPBB method discussed in Section 3. These were solved using the data presented in Section 4.1.

The results obtained by the PDIPBB method using the weighted sum and $\varepsilon$-constraint strategies are presented in Sections 4.2.1 and 4.2.2, respectively, and analysed in Section 4.2.3.

4.2.1. Strategy 1: Weighted sum method Table 4 describes the results obtained with the PDIPBB method, using the weighted sum strategy, based on the variation in $\alpha$ value, such that $\alpha \in[0,1]$. The columns in Table 4 indicate varieties that were selected for planting in the plots, with their respective costs and energy balances, for each predetermined $\alpha_{i}$ value $(i=1, \ldots, 12)$ of an efficient solution in Pareto optimal sense to the problem (nondominated solution). Notice that the obtained $\alpha$ values related to efficient solutions are not equally spaced in interval $[0,1]$.

In this case, the proposed approach solved a set of problems using different $\alpha$ values in interval [0,1]. The results found of these problems can be classified as dominated and nondominated solutions. In this way, the $\alpha$ values shown in Table 4 were selected from these and are related to the nondominated solutions of the proposed model.

Figure 2 is created based on the costs and energy balances listed in Table 4, representing the efficient solution (Pareto Frontier curve) of these values for strategy 1. From the efficient solutions, we drew a polynomial obtained by an interpolation, which is shown in Figure 2.

The spent computational time to solve the twelve presented subproblems using the integrality test of Borchers and Mitchell (1992) was 3.541 seconds, while without it, the time was 3.700 seconds.

4.2.2. Strategy 2: E-constraint method Table 2 presents the results obtained with the PDIPBB method using the $\varepsilon$ - 
Table 1 Varieties data

\begin{tabular}{llrlrrr}
\hline$i$ & Varieties & $V_{i}$ & $M b_{i}$ & $E_{C_{i}}$ & $A_{i}$ & $Q_{i}$ \\
\hline 1 & SP70-1284 & 4.74 & 13.37 & 9156.45 & 13.12 & 63.36 \\
2 & SP71-6163 & 8.72 & 23.57 & 8120 & 12.74 & 205.55 \\
3 & SP70-1143 & 7.05 & 22.14 & 8057.22 & 15.01 & 10.04 \\
4 & SP71-3146 & 10.15 & 27.42 & 8963.06 & 12.86 & 278.19 \\
5 & NA56-79 & 9.56 & 21.53 & 10231.42 & 12.84 & 205.77 \\
6 & RB72454 & 8.71 & 23.54 & 8392.47 & 15.26 & 205.03 \\
7 & RB855536 & 9.78 & 26.43 & 9259.22 & 17.05 & 258.46 \\
8 & SP79-1011 & 8.91 & 24.09 & 8277.68 & 15.8 & 10.33 \\
9 & RB855113 & 10.87 & 29.38 & 9611.14 & 17.54 & 11.73 \\
10 & RB 806043 & 12.32 & 33.3 & 8408.96 & 20.77 & 319.38 \\
11 & RB835486 & 9.08 & 20.96 & 8298.11 & 14.48 & 410.29 \\
\hline
\end{tabular}

Source Tolentino (2007).

Table 2 Additional data required to apply the methods

\begin{tabular}{lccccccccc}
\hline $\begin{array}{l}C_{c c l} \\
U S \$ t^{-1}\end{array}$ & $\begin{array}{c}C_{f} \\
L ~ k m^{-1}\end{array}$ & $\begin{array}{c}P \\
U S L^{-1}\end{array}$ & $\begin{array}{c}E c_{C C} \\
M J t^{-1}\end{array}$ & $\begin{array}{c}E c_{L} \\
M J t^{-1}\end{array}$ & $\begin{array}{c}E c_{T} \\
M J k m^{-1}\end{array}$ & $\begin{array}{c}T_{C} \\
m^{-3}\end{array}$ & $\begin{array}{c}\bar{A} \\
t h a^{-1}\end{array}$ & $\begin{array}{c}\overline{F_{l}} \\
t h a^{-1}\end{array}$ \\
\hline 7.03 & 0.125 & 0.85 & 7.56 & 57.54 & 5.25 & 54.57 & 14 & 11 \\
\hline
\end{tabular}

Source Tolentino (2007).

Table 3 Plots' data

\begin{tabular}{lll}
\hline Plot $j$ & $L_{j}(\mathrm{ha})$ & $D_{j}(\mathrm{Km})$ \\
\hline 1 & 17.6 & 14 \\
2 & 17.05 & 22 \\
3 & 18.29 & 12 \\
4 & 22.17 & 24.5 \\
5 & 21.22 & 13 \\
6 & 10.6 & 16.5 \\
7 & 13.25 & 14 \\
8 & 16.96 & 16 \\
9 & 18.7 & 20 \\
10 & 15.36 & 15.5 \\
11 & 16.84 & 23.5 \\
12 & 19.88 & 22 \\
13 & 21.82 & 29 \\
14 & 19.42 & 15 \\
15 & 21.59 & 22.5 \\
\hline
\end{tabular}

Source Tolentino (2007).

constraint strategy. Each different lower bound $\varepsilon_{i} \quad(i=$ $1, \ldots, 12)$ of an efficient solution in Pareto optimal sense to the problem was determined, considering approximate values of the energy balance obtained with strategy 1 (see Table 4) in order to validate the obtained results. Therefore, each column in Table 2 indicates the varieties selected for planting in the plots, with their respective costs and energy balances for each bounded $\varepsilon_{i}$.

Each $\varepsilon_{i}$ value used as bound was chosen based on results of the weighted sum strategy, considering the good results found in Pareto optimal curve which was determined by PDIPBB using this strategy.

Figure 3 represents the curve of the efficient solutions based on costs and energy balances obtained by PDIPBB method shown in Table 2.
The time spent by this strategy to solve twelve subproblems associated with each $\varepsilon_{i}$ was 3.507 seconds using the integrality test and 3.711 seconds without it.

4.2.3. Analysis of the results In general, a solution that satisfies the two objective functions-minimising collection and transportation costs and maximising energy balance-is not possible, since it will never be achieved by the decision maker. In other words, the strategy to solve multi-objective models is to transform them into a set of single-objective problems and so it is possible to determine the solution of each one, which may be dominated or nondominated solutions. The nondominated solutions are considered efficient solutions. Therefore, a criterion is needed for choosing the most efficient solution to the problem. In the presented case, this criterion depends on the aim of the sugar mill, which may decrease cost while maintaining a satisfactory energy balance or increase the energy balance while maintaining a satisfactory cost.

The results presented here were determined by weighting the objective functions (strategy 1) in Section 4.2.1 and solving the problems with a single-objective (strategy 2) in Section 4.2.2, separately. In both strategies, we drew Pareto optimal curve of the efficient solutions for the collection and transportation cost and the energy balance and indicated the varieties chosen for planting in the plots. For example, the solution to the problem of cost minimisation combines with the lowest cost (equivalent to $\alpha_{12}=1$ in strategy 1 and $\varepsilon_{12}=43.451 \times 10^{6} \mathrm{MJ}$ in strategy 2) with the lowest (worst) energy balance, while the solution to the problem of maximising energy balance combines the highest energy balance (equivalent to $\alpha_{1}=0$ in strategy 1 and $\varepsilon_{1}=71.608 \times 10^{6} \mathrm{MJ}$ in strategy 2 ) with the highest (worst) cost. 
Table 4 Varieties selected for each predetermined $\alpha_{i}$

\begin{tabular}{|c|c|c|c|c|c|c|}
\hline \multirow{2}{*}{ Plots j } & \multicolumn{6}{|c|}{$\alpha_{i}$ values } \\
\hline & $\alpha_{1}=0$ & $\alpha_{2}=0.350$ & $\alpha_{3}=0.375$ & $\alpha_{4}=0.450$ & $\alpha_{5}=0.514$ & $\alpha_{6}=0.547$ \\
\hline 1 & 4 & 10 & 10 & 7 & 9 & 9 \\
\hline 2 & 4 & 7 & 5 & 7 & 7 & 5 \\
\hline 3 & 10 & 10 & 10 & 9 & 9 & 9 \\
\hline 4 & 9 & 9 & 9 & 5 & 5 & 5 \\
\hline 5 & 9 & 9 & 9 & 9 & 9 & 7 \\
\hline 6 & 7 & 5 & 7 & 4 & 11 & 9 \\
\hline 7 & 7 & 5 & 10 & 10 & 10 & 10 \\
\hline 8 & 4 & 10 & 7 & 7 & 7 & 7 \\
\hline 9 & 10 & 7 & 5 & 5 & 7 & 7 \\
\hline 10 & 7 & 7 & 7 & 4 & 7 & 9 \\
\hline 11 & 4 & 5 & 5 & 7 & 1 & 1 \\
\hline 12 & 10 & 7 & 5 & 5 & 5 & 5 \\
\hline 13 & 9 & 9 & 9 & 5 & 5 & 1 \\
\hline 14 & 10 & 10 & 7 & 9 & 9 & 7 \\
\hline 15 & 9 & 9 & 9 & 9 & 5 & 5 \\
\hline Cost (US\$) & 59523.37 & 57240.79 & 54831.11 & 52554.45 & 50010.23 & 48064.75 \\
\hline Energy (MJ) & 71608908.70 & 70430766.28 & 68867858.86 & 67175675.57 & 64150510.69 & 61822553.35 \\
\hline Time (s) & 0.218 & 0.250 & 0.156 & 0.296 & 0.202 & 0.297 \\
\hline \multirow[t]{2}{*}{ Plots j } & \multicolumn{6}{|c|}{$\alpha_{i}$ values } \\
\hline & $\alpha_{7}=0.550$ & $\alpha_{8}=0.560$ & $\alpha_{9}=0.595$ & $\alpha_{10}=0.655$ & $\alpha_{11}=0.695$ & $\alpha_{12}=1$ \\
\hline 1 & 5 & 7 & 7 & 7 & 7 & 11 \\
\hline 2 & 1 & 1 & 5 & 11 & 3 & 3 \\
\hline 3 & 10 & 10 & 7 & 11 & 7 & 11 \\
\hline 4 & 5 & 1 & 1 & 1 & 1 & 1 \\
\hline 5 & 7 & 7 & 7 & 7 & 11 & 1 \\
\hline 6 & 9 & 9 & 11 & 8 & 5 & 6 \\
\hline 7 & 9 & 9 & 10 & 5 & 7 & 6 \\
\hline 8 & 7 & 7 & 7 & 10 & 11 & 3 \\
\hline 9 & 7 & 5 & 5 & 5 & 11 & 3 \\
\hline 10 & 9 & 5 & 10 & 5 & 3 & 6 \\
\hline 11 & 1 & 1 & 5 & 11 & 3 & 3 \\
\hline 12 & 5 & 5 & 1 & 1 & 1 & 11 \\
\hline 13 & 1 & 1 & 1 & 1 & 1 & 1 \\
\hline 14 & 7 & 7 & 5 & 7 & 11 & 11 \\
\hline 15 & 5 & 5 & 1 & 1 & 1 & 1 \\
\hline Cost (US\$) & 46101.25 & 43727.18 & 42695.32 & 41119.51 & 39079.78 & 37892.45 \\
\hline Energy (MJ) & 59073615.67 & 55954083.13 & 53840585.36 & 50627959.47 & 46460360.78 & 43451748.85 \\
\hline Time $(s)$ & 0.640 & 0.296 & 0.265 & 0.391 & 0.234 & 0.296 \\
\hline
\end{tabular}

Thus, it is up to the decision maker to choose the most efficient solution to meet the sugar mill needs, e.g. a solution that prioritises lower collection and transport cost and generates less energy or, alternatively, a solution aimed at higher energy production combined with higher sugar cane waste collection and transportation costs.

According to Deb (2004), Figures 2 and 3 indicate the good performance of the proposed hybrid method, because it provided a good number of efficient solutions which are well spaced in Pareto frontier.

Strategy 1 is a more complex way to solve the model, since it depends on normalising objective functions and on selecting the appropriate parameters $\alpha \in[0,1]$ to determine efficient solutions on Pareto frontier. Hence, the optimal values for the energy balance objective function obtained through strategy 1 can be used as a lower bound for this function when it is used as a constraint for solving the model defined by strategy 2 . Thus, the curve of the efficient solutions obtained by the proposed hybrid method is determined more easily through strategy 2, because strategy 2 allows one to choose any energy balance value, while the results obtained through strategy 1 come from the variation in $\alpha$ value.

For example, if the decision maker uses strategy 2 to establish an energy balance production of about $59 \times 10^{6} \mathrm{MJ}$, an analysis of efficient solutions in Pareto optimal curve (Figure 3) will indicate a solution with an energy balance of $59,000,622.56 \mathrm{MJ}$, involving collection and transportation costs of US $\$ 46,001.29$, which must be in the sugar mill interest. In this case, to reach this solution using the proposed hybrid algorithm through the primal-dual interior-point and 
branch-and-bound methods, the following choices were made: variety 1 (SP70-1284) planted in plots 2, 11 and 13; variety 5 (NA56-79) in plots 4, 9, 12 and 15; variety 7 (RB855536) in plots $1,3,5$ and 14; variety $9(\mathrm{RB} 855113)$ in plots 6,7 and 10 and variety 10 (RB806043) in plot 8 .

In comparison with other works developed in relation to the presented models, the multi-objective model presented by Florentino et al (2011) was solved using the $\varepsilon$-constraint method, which was used as strategy 2 in this work. The problem considered 4 varieties and 10 plots to meet the sugar mill constraints, but without considering the constraint of the maximum number of plots in which variety $i$ can be planted (see Equation (2.13)). The results were obtained using MATLAB software and required a longer computational time than the PDIPBB method. Tolentino (2007), in turn, presents results using the branch-and-bound 0-1 algorithm through MATLAB and Microsoft Excel software. His work involves single-objective models for waste collection and transportation costs and energy balances, which were compared with the model of strategy 1 for $\alpha=1$ and $\alpha=0$, respectively. The two studies yielded the same results.

In order to present the efficiency of the PDIPBB method and the quality of its performance, the results were compared with those obtained by IBM ILOG CPLEX Optimization Studio Version 12.5 toolkit, which combines integrated development environment (IDE) with Optimization Programming Language (OPL). Table 2 shows a performance comparison of the weighted sum strategy obtained by PDIPBB method and CPLEX. The results of the $\varepsilon$-constraint strategy using PDIPBB method and CPLEX are found in Table 3. The tables present

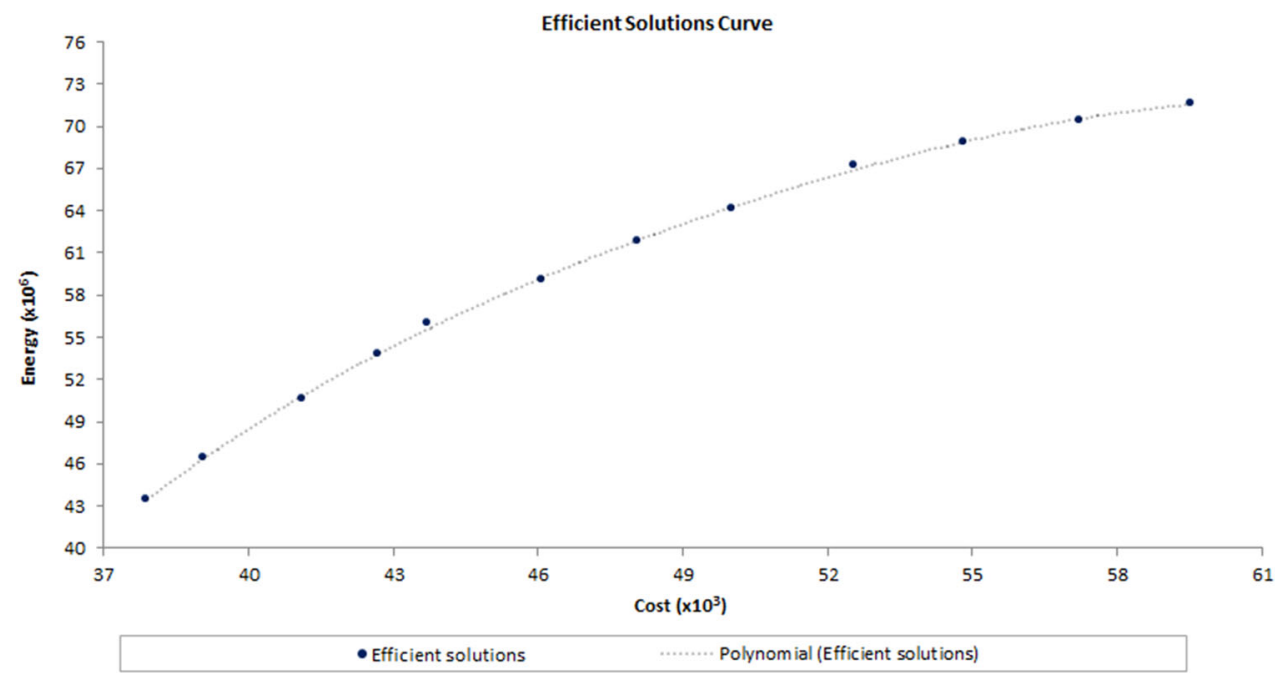

Figure 2 Efficient solutions curve for strategy 1 (Pareto Frontier).

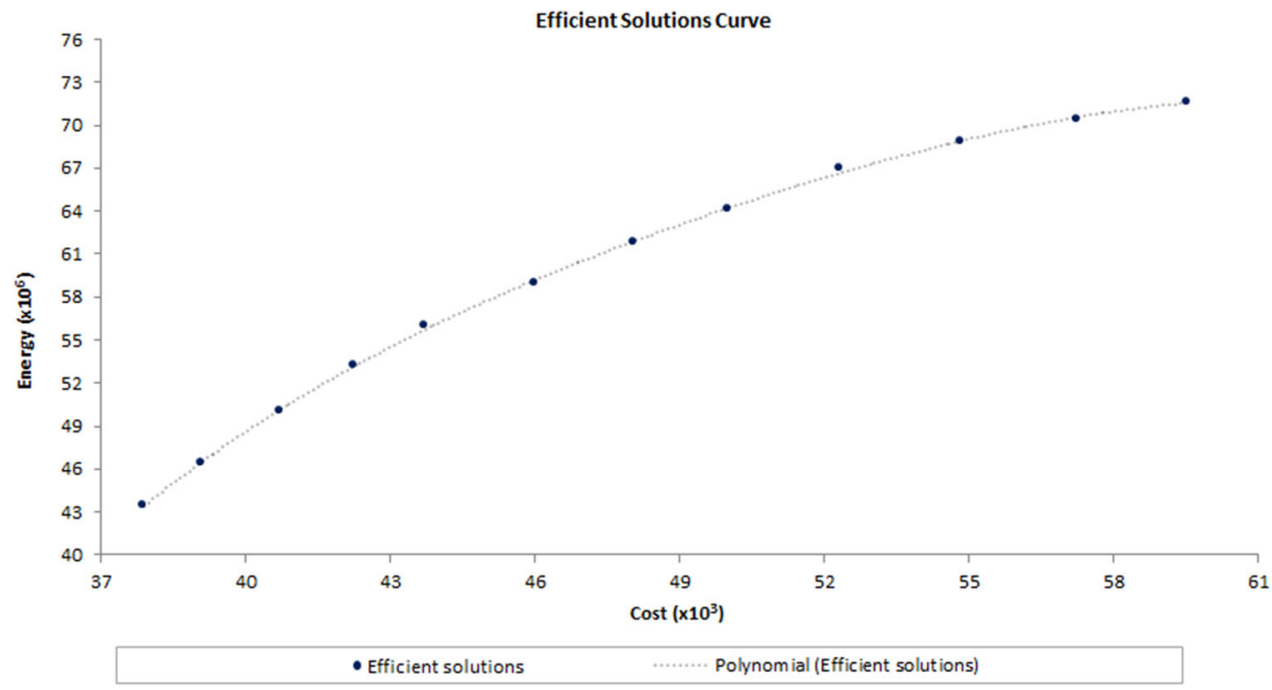

Figure 3 Efficient solutions curve for strategy 2 (Pareto Frontier). 
the cost and energy values, and the spent computational time in the resolution of the subproblems of both strategies for each solver (PDIPBB method and CPLEX ).

According to Table 2, for $\alpha$ values equal $0,0.350,0.375$, $0.450,0.547$ and 0.560 , both solvers obtained the same cost and energy values using the strategy 1 , but these values were achieved in less time with the PDIPBB method. Considering the $\alpha$ values equal $0.514,0.550,0.595,0.655$ and 0.695 , the PDIPBB method obtained the cost and energy values better than CPLEX. And in the case of $\alpha$ equals 1, CPLEX had better results.

Using the strategy 2, the PDIPBB method obtained only one better result than the CPLEX $(\varepsilon=46.467)$, and CPLEX achieved better cost and energy values for $\varepsilon$ values equal
53.259, 50.092 and 43.451. For the remaining $\varepsilon$ values, both solvers reached the same results, but in different times. In general, the PDIPBB method reached the results in less time, except $\varepsilon$ value equals 71.608. These considerations are presented in Table 3. Figures 4 and 5 illustrate the comparison between PDIPBB method and CPLEX, based on the results presented in Tables 2 and 3, respectively.

For this comparison, only the nondominated solutions were investigated by CPLEX, in other words, the twelve subproblems obtained by PDIPBB method. It is important to consider that, from a sequence of pre-established values for the $\alpha$ parameter in the strategy 1 , the PDIPBB method solves sequentially the single-objective subproblems generated, and after this resolution, the solutions are selected to refine

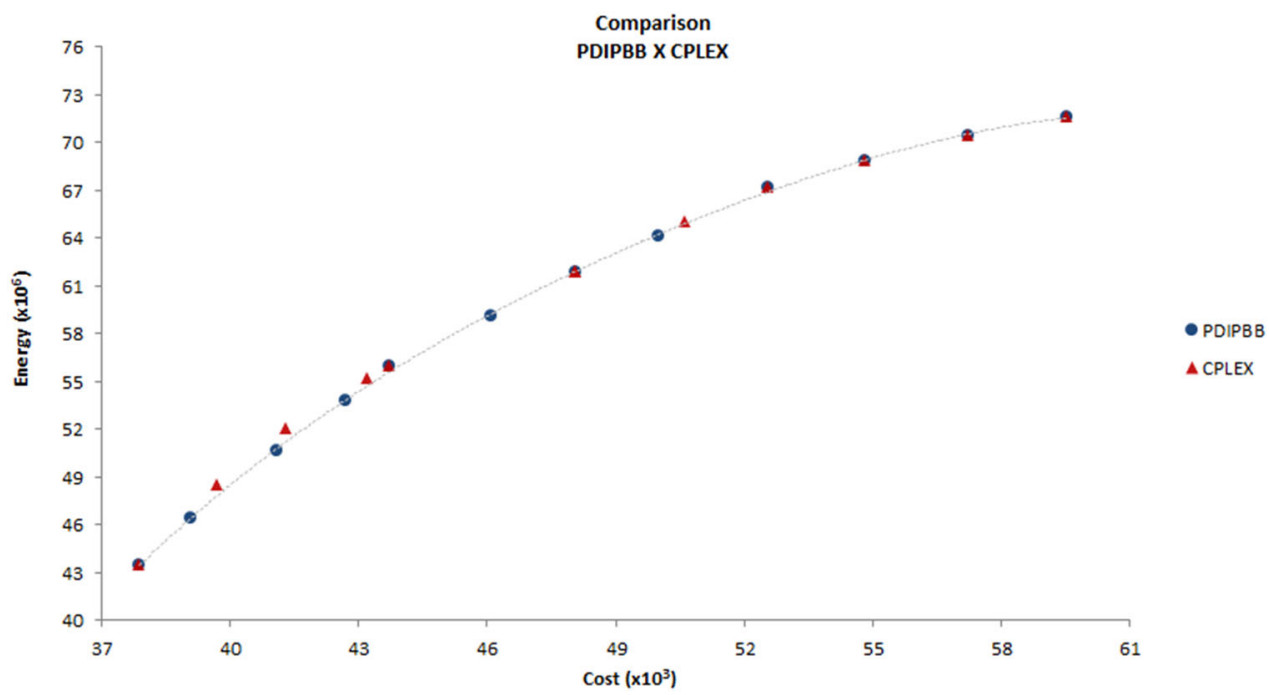

Figure 4 Efficient solutions curve for strategy 1 of PDIPBB method and CPLEX.

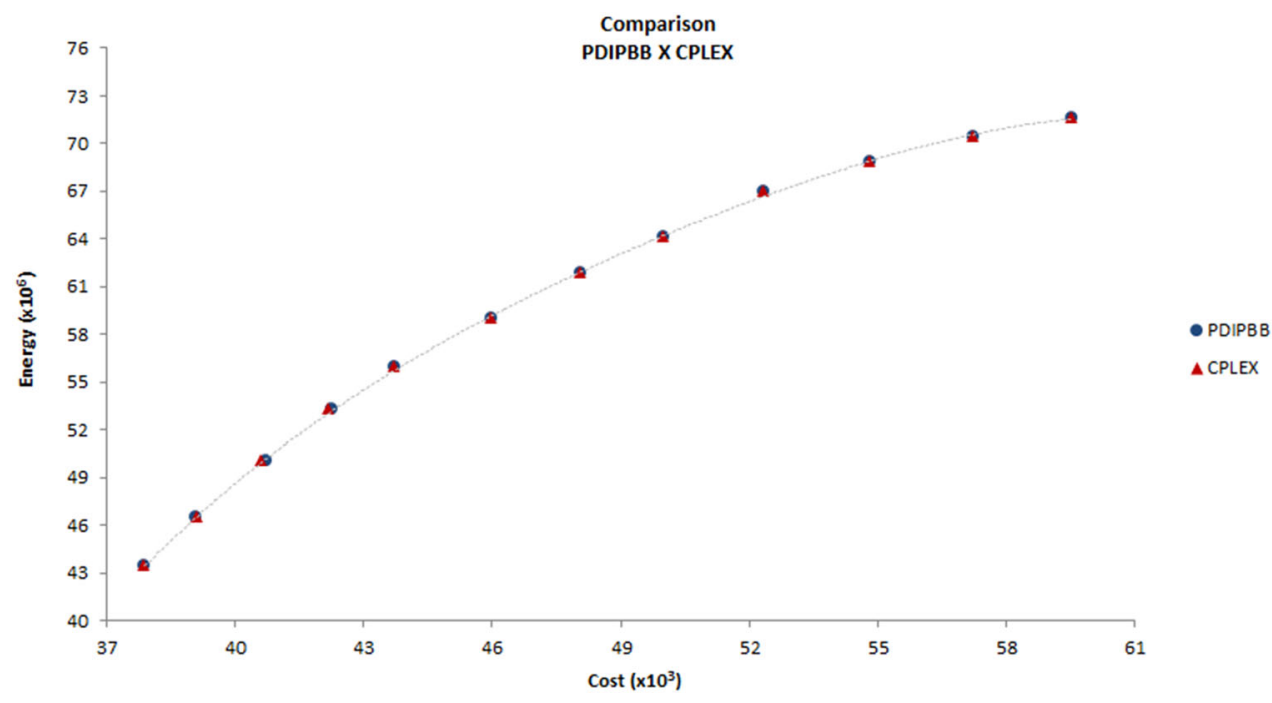

Figure 5 Efficient solutions curve for strategy 2 of PDIPBB method and CPLEX. 
Table 5 Varieties selected for each lower bound $\varepsilon_{i}$

\begin{tabular}{|c|c|c|c|c|c|c|}
\hline \multirow[t]{2}{*}{ Plots $j$} & \multicolumn{6}{|c|}{$\varepsilon_{i}$ values } \\
\hline & $\varepsilon_{1}=71.608$ & $\varepsilon_{2}=70.430$ & $\varepsilon_{3}=68.867$ & $\varepsilon_{4}=66.658$ & $\varepsilon_{5}=64.150$ & $\varepsilon_{6}=61.822$ \\
\hline 1 & 4 & 10 & 10 & 9 & 9 & 9 \\
\hline 2 & 4 & 7 & 5 & 7 & 7 & 5 \\
\hline 3 & 10 & 10 & 10 & 9 & 9 & 9 \\
\hline 4 & 9 & 9 & 9 & 5 & 5 & 5 \\
\hline 5 & 9 & 9 & 9 & 9 & 9 & 7 \\
\hline 6 & 7 & 5 & 7 & 4 & 11 & 9 \\
\hline 7 & 7 & 5 & 10 & 10 & 10 & 10 \\
\hline 8 & 4 & 10 & 7 & 7 & 7 & 7 \\
\hline 9 & 10 & 7 & 5 & 7 & 7 & 7 \\
\hline 10 & 7 & 7 & 7 & 4 & 7 & 9 \\
\hline 11 & 4 & 5 & 5 & 7 & 1 & 1 \\
\hline 12 & 10 & 7 & 5 & 5 & 5 & 5 \\
\hline 13 & 9 & 9 & 9 & 5 & 5 & 1 \\
\hline 14 & 10 & 10 & 7 & 9 & 9 & 7 \\
\hline 15 & 9 & 9 & 9 & 5 & 5 & 5 \\
\hline Cost (US\$) & 59523.37 & 57240.79 & 54831.11 & 52332.10 & 50010.23 & 48064.75 \\
\hline Energy (MJ) & 71608908.70 & 70430766.28 & 68867858.86 & 66958465.50 & 64150510.69 & 61822553.35 \\
\hline Time (s) & 0.358 & 0.374 & 0.374 & 0.375 & 0.280 & 0.468 \\
\hline
\end{tabular}

\begin{tabular}{|c|c|c|c|c|c|c|}
\hline \multirow[t]{2}{*}{ Plots $j$} & \multicolumn{6}{|c|}{$\alpha_{i}$ values } \\
\hline & $\varepsilon_{7}=59.000$ & $\varepsilon_{8}=55.954$ & $\varepsilon_{9}=53.259$ & $\varepsilon_{10}=50.092$ & $\varepsilon_{11}=46.467$ & $\varepsilon_{12}=43.451$ \\
\hline 1 & 7 & 7 & 7 & 7 & 7 & 11 \\
\hline 2 & 1 & 1 & 5 & 11 & 3 & 3 \\
\hline 3 & 7 & 10 & 7 & 6 & 7 & 11 \\
\hline 4 & 5 & 1 & 1 & 1 & 1 & 1 \\
\hline 5 & 7 & 7 & 5 & 7 & 11 & 1 \\
\hline 6 & 9 & 9 & 10 & 5 & 5 & 6 \\
\hline 7 & 9 & 9 & 10 & 6 & 7 & 6 \\
\hline 8 & 10 & 7 & 3 & 7 & 3 & 3 \\
\hline 9 & 5 & 5 & 5 & 11 & 11 & 3 \\
\hline 10 & 9 & 5 & 7 & 5 & 11 & 6 \\
\hline 11 & 1 & 1 & 5 & 11 & 3 & 3 \\
\hline 12 & 5 & 5 & 1 & 1 & 1 & 11 \\
\hline 13 & 1 & 1 & 1 & 1 & 1 & 1 \\
\hline 14 & 7 & 7 & 7 & 7 & 11 & 11 \\
\hline 15 & 5 & 5 & 1 & 1 & 1 & 1 \\
\hline Cost (US\$) & 46001.29 & 43727.18 & 42249.58 & 40730.31 & 39090.66 & 37892.45 \\
\hline Energy (MJ) & 59000622.56 & 55954083.13 & 53259992.88 & 50092139.97 & 46467480.90 & 43451478.85 \\
\hline Time (s) & 0.312 & 0.234 & 0.125 & 0.280 & 0.218 & 0.109 \\
\hline
\end{tabular}

subintervals, in order to obtain the Pareto optimal curve. To the subintervals where the strategy 1 does not obtain efficient solutions, the strategy 2 is used to search the solutions in these subintervals.

In the investigated problems, CPLEX used different methods to solve each subproblem, such as Gomory cutting-plane method, branch-and-cut, among others. As it was presented, the PDIPBB method is a hybrid approach combining interiorpoint and branch-and-bound methods. Considering that CPLEX is a complete toolkit to solve these kinds of problems and determines the most appropriate methods to solve them, the PDIPBB method had a good performance and determined the efficient solutions in less time when compared with CPLEX, according to Tables 2 and 3.

\section{Conclusions}

This paper involved the development of a hybrid method combining the predictor-corrector primal-dual interior- point and the branch-and-bound methods (PDIPBB) to solve integer programming 0-1 problems. This hybrid method, with strategies for solving multi-objective optimisation problems, was applied to find efficient solutions to the multi-objective model for sugar cane waste, aimed in minimising waste collection and transportation costs and maximising the energy balance, selecting the sugar cane varieties to be planted in the plots according to the sugar mill constraints.

Two solution strategies were used for solving multiobjective optimisation problems: the weighted sum and the $\varepsilon$-constraint methods. These strategies transformed the multi- 
Table 6 Strategy 1: comparison of PDIPBB method and CPLEX

\begin{tabular}{|c|c|c|c|c|c|c|}
\hline \multirow[t]{2}{*}{$\alpha_{i}$} & \multicolumn{3}{|c|}{$P D I P B B$} & \multicolumn{3}{|c|}{ CPLEX } \\
\hline & $\begin{array}{l}\text { Cost } \\
\text { (US\$) }\end{array}$ & $\begin{array}{c}\text { Energy } \\
(M J)\end{array}$ & $\begin{array}{c}\text { Time } \\
(s)\end{array}$ & $\begin{array}{c}\text { Cost } \\
\text { (US\$) }\end{array}$ & $\begin{array}{c}\text { Energy } \\
(M J)\end{array}$ & $\begin{array}{c}\text { Time } \\
(s)\end{array}$ \\
\hline 0 & 59523.37 & 71608908.70 & 0.218 & 59523.37 & 71608908.70 & 0.359 \\
\hline 0.350 & 57240.79 & 70430766.28 & 0.250 & 57240.79 & 70430766.28 & 0.406 \\
\hline 0.375 & 54831.11 & 68867858.86 & 0.156 & 54831.11 & 68867858.85 & 0.359 \\
\hline 0.450 & 52554.45 & 67175675.57 & 0.296 & 52554.40 & 67175675.57 & 0.639 \\
\hline 0.514 & 50010.23 & 64150510.69 & 0.202 & 50624.54 & 64974007.99 & 0.858 \\
\hline 0.547 & 48064.75 & 61822553.35 & 0.297 & 48064.75 & 61822553.35 & 0.562 \\
\hline 0.550 & 46101.25 & 59073615.67 & 0.640 & 48064.75 & 61822553.35 & 0.609 \\
\hline 0.560 & 43727.18 & 55954083.13 & 0.296 & 43727.18 & 55954083.13 & 0.796 \\
\hline 0.595 & 42695.32 & 53840585.36 & 0.265 & 43191.72 & 55179989.08 & 0.749 \\
\hline 0.655 & 41109.51 & 50627959.47 & 0.391 & 41316.08 & 51998964.00 & 0.702 \\
\hline 0.695 & 39079.78 & 46460360.67 & 0.234 & 39697.58 & 48466273.34 & 0.967 \\
\hline 1 & 37892.45 & 43451748.85 & 0.296 & 37892.45 & 43446507.48 & 0.484 \\
\hline Total time & & & 3.541 & & & 7.490 \\
\hline
\end{tabular}

Table 7 Strategy 2: comparison of PDIPBB method and CPLEX

\begin{tabular}{|c|c|c|c|c|c|c|}
\hline \multirow[t]{2}{*}{$\varepsilon_{i}$} & \multicolumn{3}{|c|}{$P D I P B B$} & \multicolumn{3}{|c|}{ CPLEX } \\
\hline & $\begin{array}{c}\text { Cost } \\
\text { (US\$) }\end{array}$ & $\begin{array}{c}\text { Energy } \\
(M J)\end{array}$ & $\begin{array}{c}\text { Time }(s) \\
(s)\end{array}$ & $\begin{array}{l}\text { Cost } \\
\text { (US\$) }\end{array}$ & $\begin{array}{c}\text { Energy } \\
(M J)\end{array}$ & $\begin{array}{c}\text { Time } \\
(s)\end{array}$ \\
\hline 71.608 & 59523.37 & 71608908.70 & 0.358 & 59523.37 & 71608908.70 & 0.312 \\
\hline 70.430 & 57240.79 & 70430766.28 & 0.374 & 57240.79 & 70430766.28 & 0.421 \\
\hline 68.860 & 54831.11 & 68867858.86 & 0.374 & 54831.11 & 68867858.85 & 0.858 \\
\hline 66.958 & 52332.10 & 66958465.50 & 0.375 & 52332.10 & 66958465.50 & 0.890 \\
\hline 64.150 & 50010.23 & 64150510.69 & 0.280 & 50010.23 & 64150510.69 & 0.609 \\
\hline 61.822 & 48064.75 & 61822553.35 & 0.468 & 48064.75 & 61822553.35 & 0.827 \\
\hline 59.000 & 46001.30 & 59000622.56 & 0.312 & 46001.30 & 59000622.56 & 1.201 \\
\hline 55.954 & 43727.18 & 55954083.13 & 0.234 & 43727.18 & 55954083.13 & 0.718 \\
\hline 53.259 & 42249.58 & 53259992.88 & 0.125 & 42202.70 & 53256662.19 & 1.667 \\
\hline 50.092 & 40730.31 & 50092139.97 & 0.280 & 40633.94 & 50092145.33 & 1.747 \\
\hline 46.467 & 39090.66 & 46467481.00 & 0.218 & 39122.08 & 46467480.90 & 1.294 \\
\hline 43.451 & 37892.45 & 43451748.85 & 0.109 & 37892.45 & 43446507.48 & 0.671 \\
\hline Total time & & & 3.507 & & & 11.215 \\
\hline
\end{tabular}

objective problem into a class of single-objective problems that were solved using the proposed hybrid PDIPBB method, implemented with Borland $\mathrm{C}++$ Builder 6.0 software.

Using these strategies, the PDIPBB method was applied to determine the efficient set of solutions to the multi-objective problem and Pareto optimal curve for each solution. The results obtained with the PDIPBB method were compared with those of IBM ILOG CPLEX Optimization Studio Version 12.5, which shown a good and competitive computational performance. Besides, the method provided reliable solutions which satisfied the sugar mill operational constraints.

Thus, the proposed hybrid PDIPBB method, exploring the strategies for solving multi-objective problems, proved to be a feasible optimisation technique for solving the multi-objective model presented here, allowing the selection of the sugar cane varieties to be planted in plots, in order to optimise sugar cane waste collection and transportation costs and the sugar mill energy balance.
Acknowledgments-The authors gratefully acknowledge the Brazilian research funding agencies CAPES (Federal Agency for the Support and Improvement of Higher Education), FAPESP (São Paulo Research Foundation, under Grant no. 2014/ 20853-0), CNPq (National Council for Scientific and Technological Development), FUNDUNESP (Foundation for the Development of UNESP) and PROPG UNESP (Postgraduate Dean's Office-UNESP) for their support of this work.

\section{References}

Andrade LAB (2001). Produção de aguardente de cana-de-açúcar, chapter Cultura da cana-de-açúcar, pp 19-49. UFLA, Lavras.

Balbo AR, Souza MAS, Baptista EC and Nepomuceno L (2012). A predictor-corrector primal-dual interior-point method for solving the multi-objective environmental economic dispatch problems: a post-optimization analysis. Mathematical Problems in Engineering. doi: $10.1155 / 2012 / 376546$

Bazaraa MS, Sherali HD and Shetty CM (1993). Non Linear Programming-Theory and Algorithm, second edition. John Wiley \& Sons: New York. 
Borchers B and Mitchell JE (1992). Using an interior point method in a branch and bound algorithm for integer programming. Technical report, Mathematical Sciences Resselaer Polytechnic Institute, Troy, NY 12180.

Brandão D, Goltz E, Carvalho MA, Rudorf BFT and Ponzoni FJ (2009). Distinção de classes de cana-de-açúcar através do ndvi. In Anais do XIV Simpósio Brasileiro de Sensoriamento Remoto, pp 105-111, Natal. São José dos Campos: IMPE.

CONAB (2015). Companhia Nacional de Abastecimento - CONAB. Acompanhamento de safra brasileira: cana-de-açúcar, Terceiro levantamento, Dezembro/2015 2(3):1-65. Companhia Nacional de Abastecimento, Brasília.

Deb K (2004). Multi-objective Optimization Using Evolutionary Algorithms. John-Willey \& Sons Ltd.

Fang SC and Puthenpura S (1993). Linear Optimization and Extensions: Theory and Algorithms. Prentice-Hall, Englewood Cliffs, NJ.

Florentino HO (2006). Programação linear inteira em problemas de aproveitamento da biomassa residual de colheita da cana-deaçúcar. $\mathrm{PhD}$ thesis, Universidade Estadual Paulista, Instituto de Biociências de Botucatu, Botucatu, SP.

Florentino HO, Lima AD, Carvalho LR, Balbo AR and Homem TPD (2011). Multi-objective 0-1 integer programming for the use of sugarcane residual biomass in energy cogeneration. International Transactions in Operational Research 18(5):605-615.

Florentino HO and Pato MV (2014). A bi-objective genetic approach for the selection of sugarcane varieties to comply with environmental and economic requirements. Journal of the Operational Research Society 65(6):842-854.

Grisotto ME (1995). Otimização do transporte de cana-de-açúcar por caminhões campinas, sp, 1995. Master's thesis, Instituto de Matemática, Estatística e Computação Científica-Universidade Estadual de Campinas.

Higgins AJ (1999). Optimizing cane supply decisions within a sugar mill region. Journal of Scheduling 2(5):229-244.

Higgins AJ and Laredo L (2006). Improving harvesting and transport planning within a sugar value chain. Journal of the Operational Research Society 57(4):367-376.

Homem TPD, Balbo AR and Florentino HO (2011). Optimal energy generation with biomass of sugarcane harvest. IEEE América Latina 1: 653-658.

Jena SD and Poggi M (2013). Harvest planning in the brazilian sugar cane industry via mixed integer programming. European Journal of Operational Research 230(2):374-384.

Karmarkar N (1984). A new polynomial time algorithm for linear programming. Combinatorica 4(4):373-395.

Kojima M, Mizuno S and Yoshise A (1989). Progress in Mathematical Programming: Interior-point and Related Methods, Chapter A Primal-dual Interior-point Method for Linear Programming, pp 29-48. Springer, New York.

Lamsal K, Jones P and Thomsa BW (2013). Sugarcane harvest logistics in brazil. Technical report, University of Iowa.

Land AH and Doig AG (1960). An automatic method of solving discrete programming problems. Econometrica 28(3):497-520.

Lavanholi MGDP (2008). Cana-de-açúcar, chapter Qualidade da cana-de-açúcar como matéria-prima para produção de açúcar e álcool, pp. 697-722. Instituto Agronômico, Campinas.

Lima AD (2009). Otimização do aproveitamento do palhiço de canade-açúcar. $\mathrm{PhD}$ thesis, Faculdade de Ciências Agronômicas, Universidade Estadual Paulista, Botucatu, SP.

Lustig IJ, Marsten RE and Shanno DF (1992). On implementing mehrota's predictor-corretor interior point method for linear programming. SIAM Journal on Optimization 2(3):435-449.

Marcotte O and Soland RM (1986). An interactive branch and bound algorithm for multiple criteria optimization. Management Science 32(1):61-75.
Mehrotra S (1992). On the implementation of a primal-dual interior point method. SIAM Journal on Optimization 2(4):572-601.

Mehrotra S and Sun J (1990). An interior point algorithm for convex quadratic programming that requires $\mathrm{o}\left(\mathrm{n}^{3.5} \mathrm{l}\right)$ arithmetic operations. Mathematics of Operations Research 15(2):342-363.

Miettinen K (1999). Nonlinear Multi-objective Optimization. Kluwer, Boston.

Milan EL, Fernandez SM and Aragones LMP (2006). Sugar cane transportation in cuba, a case study. European Journal of Operational Research 174(1):374-386.

Monteiro RDC, Adler I and Resende MC (1990) A polynomial-time primal-dual affine scaling algorithm for linear and convex quadratic programming and its power series extension. Mathematics of Operations Research 15(2):191-214.

Munari P and Gondzio J (2013). Using the primal-dual interior point algorithm within the branch-price-and-cut method. Computers and Operations Research 40(8):2026-2036.

Paiva RPO and Morabito R (2009). An optimization model for the aggregate production planning of a brazilian sugar and ethanol milling company. Annals of Operations Research 169(1):117-130.

Rangel JJA, Francisco LES, Nogueira VP, Vianna DS, and Meza EBM (2009). Modelo de simulação para o sistema de corte, carregamento e transporte de cana-de-açúcar: um estudo de caso no estado do rio de janeiro. Vértices, Campos dos Goytacazes, RJ 11(1/3):43-54.

Ripoli MLC (2002). Mapeamento do palhiço enfardado de cana-deaçúcar (saccharum ssp.) e do seu potencial energético. Master's thesis, Escola Superior de Agricultura Luiz de Queiroz-Universidade de São Paulo, Piracicaba, SP.

Ripoli TCC (1991). Utilização do material remanescente da colheita de cana-de-açúcar (saccharum ssp)_equacionamento dos balanços energético e econômico. Master's thesis, ESALQ, USP, Piracicaba, SP.

Ripoli TCC and Ripoli MLC (2004). Biomassa de cana-de-açúcar: colheita, energia e ambiente. USP-ESALQ, Piracicaba, SP.

Sartori MMP, Florentino HO, Basta C and Leão AL (2001). Determination of the optimal quantity of crop residues for energy in sugarcane crop management using linear programming in variety selection and planting strategy. Energy 26(11):1031-1040.

Silva AF, Marins FAS, and Montevechi JAB (2013). Multi-choice mixed integer goal programming optimization for real problems in a sugar and ethanol milling company. Applied Mathematical Modelling 37(9):6146-6162.

Silveira LCI, Barbosa MHP, and Oliveira MW (2002). Níveis de variedades de cana-de-açúcar predominantes nas principais regiões produtoras de cachaça de minas gerais. Informe Agropecuário, Belo Horizonte 23(217): 25-32.

Tolentino G (2007). Programação linear inteira aplicada ao aproveitamento do palhiço da cana-de-açúcar. Master's thesis, Faculdade de Ciências Agronômicas, Universidade Estadual Paulista, Botucatu, SP.

UNICA (2011) Bioeletricidade: a energia verde e inteligente do Brasil. União da Agroindústria Canavieira de São Paulo, São Paulo, prole edition. Sousa, E. L \& Macedo, I. C (coord.).

Wright SJ (1997). Primal-dual interior-point methods. SIAM.

Wu YC, Debs AS and Marsten RE (1994). A direct nonlinear predictor-corrector primal-dual interior-point algorithm for optimal power flows. IEEE Transactions on Power Systems 9(2):876-883.

Received 26 July 2013; accepted 5 July 2016 